\title{
Brown and beige fat: development, function and therapeutic potential
}

\author{
Matthew Harms \& Patrick Seale
}

\begin{abstract}
Adipose tissue, best known for its role in fat storage, can also suppress weight gain and metabolic disease through the action of specialized, heat-producing adipocytes. Brown adipocytes are located in dedicated depots and express constitutively high levels of thermogenic genes, whereas inducible 'brown-like' adipocytes, also known as beige cells, develop in white fat in response to various activators. The activities of brown and beige fat cells reduce metabolic disease, including obesity, in mice and correlate with leanness in humans. Many genes and pathways that regulate brown and beige adipocyte biology have now been identified, providing a variety of promising therapeutic targets for metabolic disease.
\end{abstract}

Sedentary living and the consumption of calorie-dense food has precipitated a steep rise in obesity throughout the developed world. This is particularly alarming because of the vast array of obesity-associated diseases, including type 2 diabetes, heart disease, insulin resistance, hyperglycemia, dyslipidemia, hypertension and many types of cancer $^{1,2}$. The end results are an expanding population of chronically ill people, staggering health care expenses and a prediction that, for the first time, the current generation will have a shorter life span than previous generations ${ }^{3-5}$. There is thus an urgent need for new weight-loss treatments.

Brown adipose tissue (BAT) is a key site of heat production (thermogenesis) in mammals that has for many decades been considered an attractive target to promote weight loss. The heat produced by BAT is essential for the survival of small mammals in cold environments and for arousal in hibernators. Brown adipocytes in BAT are packed with mitochondria that contain uncoupling protein-1 (UCP1). UCP1, when activated, short circuits the electrochemical gradient that drives ATP synthesis and thereby stimulates respiratory chain activity. Heat is generated from the combustion of available substrates ${ }^{6}$ and is distributed to the rest of the body through the circulation.

Clusters of UCP1-expressing adipocytes with thermogenic capacity also develop in white adipose tissue (WAT) in response to various stimuli ${ }^{7}$. These adipocytes have been named beige, 'brite' (brown in white), iBAT (induced BAT), recruitable BAT and wBAT (white adipose BAT). Similar to adipocytes in BAT, beige cells in mouse WAT are defined by their multilocular lipid droplet morphology, high mitochondrial content and the expression of a core set of brown

Institute for Diabetes, Obesity and Metabolism, Department of Cell and Developmental Biology, Perelman School of Medicine at the University of Pennsylvania, Philadelphia, Pennsylvania, USA. Correspondence should be addressed to P.S. (sealep@upenn.edu).

Received 9 August 2012; accepted 27 August 2013; published online 29 September 2013; doi:10.1038/nm.3361 fat-specific genes (for example, Ucp1, Cidea and Pgcla (encoding peroxisome proliferator-activated receptor- $\gamma$ coactivator $1-\alpha)$ ). Despite a common ability to undergo thermogenesis, brown and beige cells have many distinguishing characteristics and should be considered as distinct cell types (Fig. 1). First, beige cells, at least those in the mouse subcutaneous depot, do not derive from the same embryonic (Myf5 (encoding myogenic factor 5)-expressing) precursors that give rise to brown adipocytes ${ }^{8}$. Second, a number of quantitative trait loci are associated with the induced development of beige but not brown adipocytes ${ }^{9}$, suggesting that these cell types are differentially regulated. Third, brown and beige adipocytes express distinct and distinguishing gene signatures ${ }^{10,11}$. Fourth, a striking difference between the two cell types is that brown adipocytes express high levels of $U c p 1$ and other thermogenic genes under basal (unstimulated) conditions, whereas beige adipocytes express these genes only in response to activators such as agonists of the $\beta$-adrenergic receptor or peroxisome proliferator-activated receptor- $\gamma(\operatorname{Ppar}-\gamma)^{12,13}$. Importantly, this trait is fat-cell autonomous, as brown fat cells increase their expression of thermogenic genes (for example, Ucp1) during adipogenesis in culture from preadipocytes without the addition of classical activators ${ }^{14}$.

A clear question is whether brown and beige fat cells have different functions. The answer to this question is still unknown and has not been well studied. However, a recent study has suggested that fully stimulated brown and beige adipocytes contain comparable amounts of Ucp1, suggesting that they have similar thermogenic capacities ${ }^{10}$. On the basis of these findings, the name beige for these cells might be misleading and is more applicable for describing the tissue that has undergone browning rather than the $\mathrm{Ucp}^{+}{ }^{+}$adipocytes themselves. Aside from thermogenesis, it is highly probable that beige and brown adipocytes have other cell type-specific actions that have yet to be studied. For example, beige adipocytes may secrete certain factors that affect WAT function, systemic metabolism or both.

The biomedical interest in brown and beige adipocytes has centered on the capacity of these cell types to counteract metabolic disease, including obesity and type 2 diabetes. Indeed, increased activities of 


\begin{tabular}{|c|c|c|c|c|c|c|}
\hline $\begin{array}{l}\text { Immunohistochemistry } \\
\text { with anti-Ucp1 }\end{array}$ & $\begin{array}{l}\text { Location } \\
\text { in humans }\end{array}$ & $\begin{array}{l}\text { Location } \\
\text { in mice }\end{array}$ & $\begin{array}{l}\text { Developmental } \\
\text { origin in mice }\end{array}$ & $\begin{array}{l}\text { Enriched } \\
\text { markers }\end{array}$ & $\begin{array}{c}\text { Key } \\
\text { transcription } \\
\text { factors }\end{array}$ & Activators \\
\hline 起 & $\begin{array}{c}\text { Neck } \\
\text { Interscapular } \\
\text { (newborns) } \\
\text { (Perirenal?) }\end{array}$ & $\begin{array}{l}\text { Interscapular } \\
\text { Cervical } \\
\text { Axillary } \\
\text { Perirenal } \\
\text { (Endocardial?) }\end{array}$ & $\begin{array}{c}\text { Myf5 }^{+} \text {cells } \\
\text { (dermomyotome) }\end{array}$ & $\begin{array}{c}\text { Zic1 } \\
\text { Lhx8 } \\
\text { Eva1 } \\
\text { Pdk4 } \\
\text { Epsti1 } \\
\text { miR-206, miR-133b }\end{array}$ & $\begin{array}{c}\text { C/ebp } \beta \\
\text { Prdm16 } \\
\text { Pgc-1 } \alpha \\
\text { Ppar- } \alpha \\
\text { Ebf2 } \\
\text { TR }\end{array}$ & $\begin{array}{c}\text { Cold } \\
\text { Thiazolidinediones } \\
\text { Natriuretic peptides } \\
\text { Thyroid hormone } \\
\text { Fgf21, Bmp7, Bmp8b } \\
\text { Orexin }\end{array}$ \\
\hline$\stackrel{\infty}{\infty}$ & $\begin{array}{l}\text { Supraclavicular } \\
\text { (Paraspinal?) }\end{array}$ & $\begin{array}{l}\text { Interspersed } \\
\text { within WAT } \\
\text { subcutaneous } \\
\text { fat > visceral fat }\end{array}$ & $\begin{array}{c}\text { Myf5 }^{-} \text {cells } \\
\text { Pdgfr- } \alpha^{+} \\
\text {(perigonadal) }\end{array}$ & $\begin{array}{c}\text { Cd137 } \\
\text { Tbx1 } \\
\text { Tmem26 } \\
\text { Cited1 } \\
\text { Shox2 }\end{array}$ & $\begin{array}{c}\text { C/ebp } \beta \\
\text { Prdm16 } \\
\text { Pgc-1 } \alpha \\
\text { (Ppar- } \alpha ?)\end{array}$ & $\begin{array}{c}\text { Cold } \\
\text { Thiazolidinediones } \\
\text { Natriuretic peptides } \\
\text { (Thyroid hormone?) } \\
\text { Fgf21 } \\
\text { Irisin }\end{array}$ \\
\hline
\end{tabular}

Figure 1 Differences between brown and beige adipocytes. Brown adipocytes express high levels of Ucp1 under basal conditions, whereas clusters of beige adipocytes can only be easily recognized in WAT after cold or $\beta$-adrenergic stimulation. Enriched markers of brown as compared to beige adipocytes have recently been identified, including the brown markers Zic1 (ref. 12), Lhx8 (refs. 12,37), Eva1 (ref. 10) and Epsti1 (ref. 11) and the beige markers Cd137 (ref. 10), Tmem26 (ref. 10), Tbx1 (refs. 10,12), Cited1 (ref. 11) and Shox2 (ref. 25). Among the activators that have been studied in both compartments, irisin is the only one that has selective actions in beige but not brown adipocytes.

brown and beige adipocytes have been linked to obesity resistance in many mouse models ${ }^{15-17}$ (Table 1). In humans, it was assumed for many years that there was too little brown fat present in adults to affect body weight. However, a few years ago, imaging studies revealed the presence of substantial deposits of UCP1-expressing adipocytes in adult humans, the mass, activity or both of which were lower in obese and older subjects ${ }^{18-22}$. The key question now is whether reduced thermogenic activity in fat cells is a cause or a consequence of weight gain in humans. Regardless of its natural role, increasing the activity of brown fat, beige fat or both through drugs or other methods holds tremendous promise for the treatment of metabolic disease.
Mitochondrial uncoupling has been tried as a weight-loss therapy. The chemical uncoupler 2,4-dinitrophenol (DNP) allows protons to leak across the mitochondrial membrane, mimicking the effect of activated UCP1 (ref. 23). In the 1930s, DNP was used widely as an effective diet pill to treat obesity, providing proof-of-concept support for mitochondrial uncoupling as an approach for weight loss. However, at high doses (which vary in different people), unregulated respiratory uncoupling in all cells causes dangerous side effects, including hyperthermia and death. Thus, the goal should be to develop strategies that enhance respiratory uncoupling selectively in adipose tissue by exploiting the mechanisms that naturally evolved to do this in brown and beige fat cells.

Table 1 Mouse models resistant to weight gain through enhanced brown and beige fat activity

\begin{tabular}{|c|c|c|c|c|}
\hline Gene & $\begin{array}{l}\text { Induces } \\
\text { beige fat }\end{array}$ & $\begin{array}{l}\text { Increases } \\
\text { brown fat }\end{array}$ & Comments & References \\
\hline \multicolumn{5}{|c|}{ Gain-of-function models } \\
\hline $\begin{array}{l}\text { Ptgs2 (also known } \\
\text { as Cox2) }\end{array}$ & Yes & $\begin{array}{l}\text { Not } \\
\text { determined }\end{array}$ & $\begin{array}{l}\text { Cox } 2 \text {-overexpressing mice have increased beige fat and are resistant to weight gain, demonstrating } \\
\text { the role of prostaglandins in the recruitment of beige fat. }\end{array}$ & 147 \\
\hline Foxc2 & Yes & Yes & $\begin{array}{l}\text { Overexpression of Foxc } 2 \text { in adipose increases the expression of the } \mathrm{R} 1 \alpha \text { regulatory subunit of PKA, } \\
\text { making the cells more sensitive to catecholamines. }\end{array}$ & $15,82,85$ \\
\hline Prdm 16 & Yes & No & Mice selectively transgenic for Prdm16 in fat have increased beige fat. & 16 \\
\hline Pten & Yes & Yes & Increases in Pten levels inhibit PI3K, which drives a thermogenic program. & 148 \\
\hline Ucp1 & Yes & No & Transgenic expression of $U_{c p 1}$ increases thermogenesis in WAT and prevents weight gain. & 17,149 \\
\hline \multicolumn{5}{|c|}{ Loss-of-function models } \\
\hline Acvr $2 b$ & No & Yes & $\begin{array}{l}\text { Neutralizing antibodies to ActRIIB lead to an increase in BAT mass without affecting WAT. Loss of } \\
\text { ActRIIB activates Smad3 signaling to increase expression of thermogenic genes. }\end{array}$ & 150,151 \\
\hline Adrbk1 & Yes & Yes & $\begin{array}{l}\text { Increased core temperature and thermogenic program in BAT and WAT. Interestingly, the } \\
\text { phenotype seems to be age related. }\end{array}$ & 152 \\
\hline $\begin{array}{l}\text { Acot11 (also known } \\
\text { as Them1) }\end{array}$ & No & Yes & $\begin{array}{l}\text { Increased expression of in thermogenic genes in BAT and a decreased expression of markers of } \\
\text { inflammation in WAT. }\end{array}$ & 153 \\
\hline Aldhla1 & Yes & No & $\begin{array}{l}\text { Build up of retinaldehyde leads to activation the retinoic acid receptor, which recruits Pgc- } 1 \alpha \text { to } \\
\text { the Ucpl promoter. }\end{array}$ & 154 \\
\hline Arrdc3 & Yes & Yes & $\begin{array}{l}\text { Arrdc } 3 \text { interacts directly with } \beta \text {-ARs. Loss of Arrdc } 3 \text { sensitized adipocytes to catecholamines and } \\
\text { thus increased thermogenic programs in BAT and WAT. }\end{array}$ & 155 \\
\hline Atg7 & Yes & Yes & $\begin{array}{l}\text { BAT showed increased amounts of thermogenic proteins, and WAT had increased expression } \\
\text { of thermogenic gene signatures. Studies have demonstrated a role for autophagy in adipose } \\
\text { development. }\end{array}$ & 156 \\
\hline Atf4 & Yes & Yes & $\begin{array}{l}\text { WAT showed increased expression of Pgc-1 } \alpha \text { and Ucp2, and BAT was enriched for expression of } \\
\text { Ucp1 and Ucp3. }\end{array}$ & 157 \\
\hline Bace 1 & No & Yes & Increased expression of Ucp1 in BAT and of Ucp2 and Ucp3 in skeletal muscle. & 158 \\
\hline Cidea & No & Yes & $\begin{array}{l}\text { Knockout (KO) mice are lean, have increased oxygen consumption and defend core temperature } \\
\text { against cold challenge. Direct interactions with Ucp1 could explain the repressive effect of Cidea. }\end{array}$ & 159 \\
\hline
\end{tabular}


Table 1 (continued)

\begin{tabular}{|c|c|c|c|c|}
\hline Gene & $\begin{array}{l}\text { Induces } \\
\text { beige fat }\end{array}$ & $\begin{array}{l}\text { Increases } \\
\text { brown fat }\end{array}$ & Comments & References \\
\hline Cidec & Yes & No & $\begin{array}{l}\text { Increased expression of BAT-specific genes and of mitochondrial genes in WAT. The mechanism } \\
\text { is thought to involve loss of pRb and Rip } 140 \text {. }\end{array}$ & 160 \\
\hline Cnr1 & Yes & $\begin{array}{l}\text { Not } \\
\text { determined }\end{array}$ & $\begin{array}{l}\text { KO mice are lean. In vitro, cannabinoid receptor type } 1 \mathrm{~m} \text { antagonists can induce Ucp1 } \\
\text { transcription in white adipocytes. }\end{array}$ & 161 \\
\hline $\begin{array}{l}\text { Crfr2 (also known } \\
\text { as Crhr2) }\end{array}$ & $\begin{array}{l}\text { Not } \\
\text { determined }\end{array}$ & Yes & Increased glucose tolerance and increased Ucp1 expression in BAT. & 162 \\
\hline $\begin{array}{l}\text { DIk1 (also known } \\
\text { as Pref1) }\end{array}$ & $\begin{array}{l}\text { Not } \\
\text { determined }\end{array}$ & Yes & $\begin{array}{l}\text { BAT has increased expression of Pgc- } 1 \alpha \text { and Ucp } 1 . \text { C/ebp } \beta \text { binds and activates the } \\
\text { Pref1 promoter. }\end{array}$ & 163 \\
\hline Eif4ebp 1 & Yes & No & $\begin{array}{l}\text { Increased metabolic rate, induction of thermogenic genes in WAT depots and increased elF4F } \\
\text { phosphorylation. }\end{array}$ & 164 \\
\hline Eif4ebp2 & No & Yes & $\begin{array}{l}\text { Treatment with an antisense oligonucleotide to Eif4ebp2 caused weight loss and increased } \\
\text { expression of the } \beta 3-A R \text { in WAT and BAT. BAT showed a Pgc- } 1 \alpha \text {-independent increase in } \\
\text { Ucp1 expression. }\end{array}$ & 165 \\
\hline Ffar2 & $\begin{array}{l}\text { Not } \\
\text { determined }\end{array}$ & Yes & Resistance to weight gain and increased core temperature. & 166 \\
\hline Foxo1 & $\begin{array}{l}\text { Not } \\
\text { determined }\end{array}$ & Yes & $\begin{array}{l}\text { Mice expressing a dominant-negative form of Foxol in their adipose tissue had increased oxygen } \\
\text { consumption and a BAT-specific increase in thermogenesis. }\end{array}$ & 167 \\
\hline Ghsr & $\begin{array}{l}\text { Not } \\
\text { determined }\end{array}$ & Yes & Mice are protected from the age-associated decline of thermogenesis. & 168 \\
\hline Id1 & No & Yes & Increased oxygen consumption and an increased expression of thermogenic genes in BAT. & 169 \\
\hline Ikbke & Yes & $\begin{array}{l}\text { Not } \\
\text { determined }\end{array}$ & WAT has increased amounts of Ucp1 transcripts and protein. & 170 \\
\hline Lipe & Yes & $\begin{array}{l}\text { Not } \\
\text { determined }\end{array}$ & The increased expression in Ucp1 is attributed to a decrease in Rip140 and pRb expression. & 171 \\
\hline $\operatorname{Lrp} 6$ & Yes & Yes & $\begin{array}{l}\text { KO mice gain less weight than controls, and diminished mTORC1 activity in BAT causes an } \\
\text { increase in the expression of thermogenic proteins. }\end{array}$ & 172 \\
\hline Mstn & Yes & $\begin{array}{l}\text { Not } \\
\text { determined }\end{array}$ & Increased thermogenic program in WAT. & 173 \\
\hline Npr3 & Yes & Yes & $\begin{array}{l}\text { Loss of the natriuretic peptide clearance receptor causes increased concentrations of circulating } \\
\text { natriuretic peptides, which increase thermogenic activity. }\end{array}$ & 64 \\
\hline $\begin{array}{l}\text { Ncoa2 (also known } \\
\text { as Tif2) }\end{array}$ & $\begin{array}{l}\text { Not } \\
\text { determined }\end{array}$ & Yes & $\begin{array}{l}\text { Tif2 competes with the activator Src } 2 \text { for Pgc- } 1 \alpha \text { binding. Tif } 2 \text { binding prevents Pgc- } 1 \alpha \text { from } \\
\text { interacting with Ppar- } \gamma \text {. }\end{array}$ & 174 \\
\hline $\begin{array}{l}\text { Nr1h3 (also known } \\
\text { as Lxra) }\end{array}$ & Yes & Yes & $\begin{array}{l}\text { RIP140 is recruited by Lxra to displace Ppar- } \gamma \text {. Pgc- } 1 \alpha \text { also binds to this site, but its occupancy } \\
\text { doesn't seem to change. }\end{array}$ & 109 \\
\hline $\begin{array}{l}\text { Nrip1 (also known } \\
\text { as Rip140) }\end{array}$ & Yes & No & $\begin{array}{l}\text { Rip140 interacts directly with Pgc- } 1 \alpha \text { to inhibit its transcriptional activity. Rip140 recruits } \\
\text { chromatin modifiers such as DNA methyltransferases and histone methyltransferases to } \\
\text { silence Ucp1. }\end{array}$ & $175-177$ \\
\hline Oprd1 & $\begin{array}{l}\text { Not } \\
\text { determined }\end{array}$ & Yes & Mice are resistant to weight gain and have enhanced thermogenesis in BAT. & 178 \\
\hline Pctp & $\begin{array}{l}\text { Not } \\
\text { determined }\end{array}$ & Yes & BAT showed enlarged mitochondria and an increased expression of thermogenic genes. & 179 \\
\hline Prkar2b & $\begin{array}{l}\text { Not } \\
\text { determined }\end{array}$ & Yes & $\begin{array}{l}\text { Loss of Prkar } 2 b \text { causes a compensatory increase in the amount of RI } \alpha \text {, which binds cAMP with } \\
\text { higher affinity than Pkar } 2 b \text {, causing increased basal PKA activity and increased thermogenesis. }\end{array}$ & 180 \\
\hline Prkcb & Yes & Yes & $\begin{array}{l}\text { WAT had increased expression of } \beta 1 \text { and } \beta 3 \text { adrenergic receptors. This resulted in a p38-MAPK- } \\
\text { mediated increase in the expression of } P g c 1 \text { a and } U c p 1 \text {. }\end{array}$ & 181 \\
\hline Prlr & Yes & $\begin{array}{l}\text { Not } \\
\text { determined }\end{array}$ & $\begin{array}{l}\text { Prolactin-receptor KO mice have increased expression of thermogenic genes and altered amounts } \\
\text { of } \mathrm{pRb} \text { and Foxc2 in WAT. This indicates a new paracrine or endocrine role of prolactin. }\end{array}$ & 182 \\
\hline $\begin{array}{l}\text { Rb/1 (also known as } \\
\text { p107) }\end{array}$ & Yes & Yes & Loss of p107 causes a loss of pRb and increased expression of thermogenic genes. & 106 \\
\hline Scd1 1 & Yes & Yes & $\begin{array}{l}\text { Mice with skin-specific KO of } S c d 1 \text { have increased thermogenesis in BAT and WAT, indicating } \\
\text { crosstalk between the different tissues }\end{array}$ & 183 \\
\hline Sfrp5 & Yes & $\begin{array}{l}\text { Not } \\
\text { determined }\end{array}$ & $\begin{array}{l}\text { KO mice are resistant to weight gain, and isolated KO adipocytes have increased oxidative } \\
\text { respiration. }\end{array}$ & 184 \\
\hline Smad3 & Yes & No & $\begin{array}{l}\text { Smad3 represses Pgc- } 1 \alpha \text { expression. Loss of Smad3 induces the expression of transcripts that } \\
\text { correspond to increased thermogenesis. }\end{array}$ & 185 \\
\hline Tnfrsfla & $\begin{array}{l}\text { Not } \\
\text { determined }\end{array}$ & Yes & $\begin{array}{l}\text { Increased expression of Ucp1 in BAT and of Ucp3 in muscle, resulting in increased oxygen } \\
\text { consumption. }\end{array}$ & 186 \\
\hline Trpv4 & Yes & $\begin{array}{l}\text { Not } \\
\text { determined }\end{array}$ & $\begin{array}{l}\text { KO mice are resistant to weight gain and have increased thermogenic gene expression in WAT } \\
\text { mediated by a loss of ERK1- and ERK2-mediated effects on Pgc-1 } \alpha \text {. }\end{array}$ & 187 \\
\hline Twist1 & $\begin{array}{l}\text { Not } \\
\text { determined }\end{array}$ & Yes & Twist 1 binds to and inhibits Pgc- $1 \alpha$ activity at target genes. & 188 \\
\hline Vegfa & Yes & No & Induction of the thermogenic program in WAT with associated resistance to weight gain. & 95 \\
\hline Vgf & Yes & Yes & $\begin{array}{l}\text { KO of the secreted protein Vgf caused increased expression of Ucp1 in WAT and BAT. Unclear } \\
\text { whether the effect is cell autonomous. }\end{array}$ & 189 \\
\hline
\end{tabular}


Figure 2 Transcriptional regulation of brown and beige adipocyte development. (a) Brown adipocytes are derived from a Myf5-expressing progenitor population. Ebf2 cooperates with Ppar- $\gamma$ to promote the expression of Prdm16, which drives a brownfat cell fate. Thermogenesis in mature brown adipocytes is activated by norepinephrine (NE), a $\beta 3$ agonist, released from sympathetic neurons. NE signals through $\beta$-adrenoreceptors to increase the expression and activity of Pgc- $1 \alpha$, a transcriptional coactivator that coordinates gene programming in response to activation. (b) In inguinal fat, $\beta$-adrenergic stimulation triggers predominantly de novo differentiation of precursor cells (large arrow). We leave open the possibility that under some conditions, mature white fat cells can transdifferentiate into beige cells (small dashed arrow). In epididymal WAT, caloric excess causes bipotent progenitors to differentiate into white adipocytes, whereas $\beta$-adrenergic activators stimulate beige adipocyte development. TZD agonists of Ppar- $\gamma$ promote beiging both by increasing the stability of Prdm16 and through the Sirt1-dependent deacetylation of Ppar- $\gamma$, which recruits Prdm16 to Ppar- $\gamma$ target genes. $\beta$-adrenergic signaling drives the expression and activity of Pgc- $1 \alpha$ in beige adipocytes. Pgc- $1 \alpha$ is targeted by numerous repressors to block beige adipocyte development. Ac, acetylation.

\section{Development of brown and beige adipocytes}

Brown adipocytes. BAT forms during embryonic development before other fat depots and is assumed to contain a uniform population of adipocytes. The major BAT depots in rodents are in the interscapular region (interscapular, axillary and cervical pads) embedded in and around deep back muscles. An interscapular BAT depot has also been noted in human infants, which regresses and is absent in adults ${ }^{24,25}$. Most brown fat cells originate from precursor cells in the embryonic mesoderm that also give rise to skeletal muscle cells and a subpopulation of white adipocytes $8,26,27$. These precursors transiently express Myf5 and Pax7, two genes that were previously thought to selectively mark skeletal myogenic cells in the mesoderm ${ }^{8,27}$ (Fig. 2a). Consistent with a developmental relationship between brown fat and muscle, brown fat precursor cells express a muscle-like gene signature ${ }^{28}$, and brown fat and muscle have related mitochondrial proteomes ${ }^{29}$. However, whether Myf5-expressing cells are multipotent or whether there are separate pools of $M y f 5$-expressing precursors that contribute to muscle, brown fat and white fat remains to be tested.

Beige adipocytes. The embryonic origin and cell hierarchy of beige adipocytes is less clear. Beige and brown adipocytes probably come from distinct cell lineages, given that beige cells, at least in the subcutaneous depot, do not have a history of $M y f 5$ expression $^{8,26}$. In formed WAT, an important question is whether beige adipocytes come from white adipocytes through transdifferentiation or arise through the de novo differentiation and maturation of precursors. Over a decade ago, Himms-Hagen et al. ${ }^{30}$ found that most beige adipocytes arise from pre-existing (nondividing) cells that they presumed were mature adipocytes. Since then, Cinti and others have provided substantial evidence in support of the idea that large unilocular white adipocytes transform into beige adipocytes in response to cold or $\beta 3$-adrenergic agonists ${ }^{7}$.

A new study from Wang et al. ${ }^{31}$ used a pulse-chase fate-mapping technique in mice to revisit this issue. The authors pulse labeled mature adipocytes in WAT using LacZ. This labeling was indelible and heritable such that LacZ was constitutively expressed in the pulsed adipocytes and any of their descendents. After being pulsed, the mice were exposed to cold or treated with $\beta 3$-adrenergic agonists to induce the formation of beige adipocytes. The results were clear-the majority of newly acquired $U c p 1^{+}$adipocytes in the subcutaneous inguinal depot were not marked by LacZ. This indicates that most, if not all, beige adipocytes (at least in this subcutaneous depot) arise from a precursor

The thermogenic profile of beige adipocytes is reversible. Beige adipocytes acquired in WAT during cold exposure lose Ucp 1 expression and are retained after mice are moved back to warmer conditions $^{32}$ (Fig. 2b). When these mice are re-exposed to cold, the same cells again induce Ucp1 expression ${ }^{32}$. Interestingly, the cells marked by previous Ucp 1 expression were not the only source of beige adipocytes during the second round of cold exposure. This suggests that beige adipocytes are retained and may function similarly to white fat cells for a certain period of time in animals that were previously cold. These beige adipocytes are presumably depleted through the normal mechanisms that control tissue turnover.

Another important question is whether beige and white adipocytes arise from different types of precursors. Petrovic et al. ${ }^{12}$ found that a subset of adipocytes differentiated in vitro from the stromal vascular fraction (an enriched source of preadipocytes) of WAT induce Ucp1 expression in response to treatment with PPAR- $\gamma$ activators; this suggests that some but not all preadipose cells are thermogenically competent. Recently, the Spiegelman laboratory used limited dilutions to clone preadipocyte cell lines from the stromal vascular fraction of subcutaneous (inguinal) WAT ${ }^{10}$. Through global gene profiling and differentiation analyses, the authors identified two types of preadipocytes-white and beige. Both types of committed precursors differentiated into lipid-laden adipocytes that lacked thermogenic characteristics under standard adipogenic conditions. However, only beige cells induced a thermogenic gene program when treated with $\beta$-adrenergic agonists. Notably, Cd137 and transmembrane population rather than from pre-existing adipocytes (Fig. 2b). 


\section{REVIEW}

protein 26 (Tmem26) were identified as cell-surface markers for native beige precursors, thus enabling the direct purification of these cells from fat tissues. These data suggest that cold (through $\beta$-adrenergic agonists) triggers the differentiation of $\mathrm{Cd} 137^{+} \mathrm{Tmem} 26^{+}$precursor cells into $\mathrm{Ucp}^{+}$beige adipocytes and that beige cells require constant stimulation to maintain their thermogenic programming. In light of these recent studies, there does not seem to be much or any direct transformation of white into beige adipocytes, at least under physiological conditions.

Beige adipocytes are most abundant in the inguinal WAT, which is a major subcutaneous depot in rodents ${ }^{7}$. However, Ucp1-expressing adipocytes are evident in most (if not all) WAT depots in response to cold exposure $7,30,33$. In perigonadal (visceral) fat of male mice, beige adipocytes develop from a population of precursors that also differentiates into white adipocytes ${ }^{34}$ (Fig. 2b). These bipotent precursors express platelet-derived growth factor receptor- $\alpha$ (Pdgfr- $\alpha$ ) and are closely associated with blood vessels. After treatment of mice with $\beta 3$-adrenergic agonists, these precursor cells proliferate, lose Pdgfr- $\alpha$ expression and differentiate into $\mathrm{Ucp}^{+}$adipocytes. Conversely, a high-fat diet stimulates the differentiation of Pdgfr- $\alpha^{+}$cells into white adipocytes ${ }^{34}$. This result is consistent with the finding that most or all white adipocytes descend from Pdgfra-expressing cells ${ }^{35}$. Importantly, cell-culture analyses have shown that single Pdgfr- $\alpha^{+}$cells can give rise to both $\mathrm{Ucp}^{-}$and $\mathrm{Ucp}^{+}$(beige) adipocytes ${ }^{34}$.

In the mature adipocyte tracing studies of Wang et al. ${ }^{31}$, very little beige fat recruitment, but a surprising amount of white adipogenesis, was detected in the perigonadal WAT of mice exposed to cold for 1-3 d or treated with a $\beta 3$ agonist for $7 \mathrm{~d}$. Why new white fat cells develop during cold exposure is unclear. It is also surprising that so few Ucp $1^{+}$ cells were detected. Perhaps the exposure was too short to elicit a full beige recruitment in the newly developed adipocytes? It would be interesting to examine the effects of chronic cold in these mice, as this is known to lead to the extensive browning of WAT depots.

The prevalence of beige adipocytes within different human WAT depots has not been carefully evaluated. However, it is known that human WAT contains precursor cells that are capable of expressing UCP1 and other brown and/or beige characteristics, particularly in response to PPAR- $\gamma$ activation ${ }^{36}$. Additionally, it was (and still is) unclear whether the deposits of UCP1-expressing adipocytes identified by fluorodeoxyglucose positron emission tomography (FDGPET) in adult humans are analogous to beige or brown fat. Wu et al. ${ }^{10}$ and Sharp et al. ${ }^{11}$ reported that supraclavicular tissue, the largest FDG-PET-positive depot in humans, expresses selective markers of beige fat cells. By contrast, Jesperson et al. ${ }^{37}$ found that tissue and in vitro-differentiated adipocytes from this depot express both brownand beige-specific markers. A different depot in the neck region was shown to have the molecular characteristics of mouse brown fat $^{38}$. Typing these depots as brown or beige on the basis of their expression levels of a few mouse marker genes that have no known function(s) has not been conclusive thus far. Functional marker genes or assays are needed to better categorize the different human and mouse fat depots and cell types, and researchers should continue to study the biology and therapeutic potential of both classic BAT and inducible beige fat.

\section{Regulation of brown and beige adipocytes by PRDM16}

Prdm 16 is a large zinc finger-containing transcriptional factor that is highly expressed in mouse BAT relative to visceral WAT ${ }^{39}$. PRDM16 expression is also substantially enriched in human BAT relative to adjacent subcutaneous WAT ${ }^{22,40}$. Ectopic Prdm16 expression converts myoblasts and white fat precursors into thermogenic, Ucp1-containing adipocytes $^{8}$. Mechanistic studies have suggested that Prdm16 acts primarily through binding to and modulating the activity of other transcriptional factors, including c/EBP $\beta, \operatorname{Ppar}-\gamma, \operatorname{Ppar}-\alpha$ and Pgc- $1 \alpha^{8,39,41,42}$. Knockdown of Prdm16 ablates the thermogenic characteristics of brown fat cells while also causing an increase in the expression of white fat-specific and muscle-specific genes ${ }^{8,39}$. Together these studies have strongly suggested that PRDM16 is a key driver of brown fat cell fate.

The importance of Prdm16 in brown fat cell differentiation prompted us to examine whether Prdm16 also has a role in the development of beige adipocytes. After analyzing various mouse WAT depots, we noted that Prdm16 is highly expressed in the depots that are most prone to beiging, especially the inguinal WAT ${ }^{16}$. Importantly, reduction of Prdm16 expression blocks the induction of a thermogenic program in cultured subcutaneous adipocytes and decreases the recruitment of beige adipocytes in WAT in response to $\beta$-adrenergic or Ppar- $\gamma$ agonists ${ }^{16,43}$. Conversely, transgenic expression of Prdm16 in adipose tissues of mice stimulates beige adipocyte development to counteract high fat diet-induced weight gain and improve glucose tolerance ${ }^{16}$.

Several factors have been shown to regulate brown and beige adipocyte differentiation by modulating Prdm16 expression or activity. Notable among these factors is bone morphogenetic protein 7 (Bmp7), a signal that is essential for brown fat development, which increases the amounts of Prdm 16 mRNA in brown and white fat precursor cells ${ }^{44-46}$. Additionally, thiazolidinediones (TZDs), which agonize Ppar- $\gamma$, induce thermogenic gene expression in fat cells through effects on Prdm16 (refs. 43,47). Interestingly, the muscle-enriched microRNA miR-133 directly targets and reduces the amounts of Prdm 16 to block both brown and beige adipose development ${ }^{46-48}$. Cold exposure suppresses miR-133 expression in fat cells, which leads to increased amounts of Prdm16 and increased expression of downstream thermogenic target genes ${ }^{48}$. Compared with wild-type mice, mice lacking miR-133 express higher levels of Prdm16 in WAT and develop more beige adipocytes ${ }^{49}$. Intriguingly, miR-133 is also highly expressed in mouse adult muscle stem cells, where it suppresses $\operatorname{Prdm} 16$ expression ${ }^{50}$. Reduction of miR-133 in regenerating muscle causes the ectopic development of brown adipocytes and an associated increase in energy expenditure.

\section{Roles of brown and beige fat in regulating metabolism}

BAT has long been viewed as a tissue that is key for maintaining body temperature in response to cold. In 1979, Rothwell and Stock first reported that BAT was also activated in rodents when they overeat as a mechanism to preserve energy balance and limit weight gainso-called diet-induced thermogenesis ${ }^{51}$. Consistent with this mechanism, mice genetically engineered to have less BAT gain more weight than control mice ${ }^{52}$. However, for many years it was unclear why Ucp1-deficient mice, which are cold intolerant (and thus have defective BAT), resisted rather than developed obesity ${ }^{53}$.

An important study by the Cannon and Nedergaard group revealed that Ucp1-deficient mice gain more weight than wild-type controls but only when they are housed under thermoneutral $\left(28-30{ }^{\circ} \mathrm{C}\right)$ conditions ${ }^{54}$. At room temperature $\left(20-22{ }^{\circ} \mathrm{C}\right)$, mice are cold and must therefore expend extra energy to defend their body temperature. Ucp1-deficient mice, which cannot use BAT, activate alternative thermogenic mechanisms ${ }^{55,56}$. This is thought to conceal the effect of brown fat and Ucp1 on energy balance. Consistent with this idea, old Ucp1-deficient mice, which are larger and less cold sensitive than 
younger mice, become obese even at ambient temperature ${ }^{57}$. The marked impact of temperature on physiology has been overlooked by much of the rodent research community. In the area of metabolism, cold stress and its effects have undoubtedly confounded many studies. Because people tend to live at thermoneutrality with the aid of clothing and heating, a compelling argument could be made that most or even all metabolic studies in mice should be conducted under thermoneutral conditions.

The obesogenic effect of Ucpl deficiency in warm mice indicates that the activity of brown fat, beige fat or both can affect energy balance, but the magnitude (and importance) of this effect in freeliving mice or humans is uncertain. Notably, previous studies in rats housed at thermoneutrality failed to find any substantial contribution of BAT activity to diet-induced thermogenesis ${ }^{58}$. Moreover, Anunciado-Koza et al. ${ }^{55}$ did not observe changes in adiposity in their studies of Ucp1 knockout mice when the mice were housed under varying temperature conditions. In addition, increases in BAT or Ucp1 activity in response to high-fat feeding are not consistently observed ${ }^{59}$. These divergent findings may provide an opportunity to identify modifying factors that affect BAT or Ucp 1 activity and energy balance. Are there specific dietary components that are needed to recruit BAT efficiently? What are the genetic or strainspecific effects? Do the microbiome or other environmental factors in different vivariums play a part?

Regardless of whether BAT has a major physiological role in body weight regulation in mice and humans, there is no question that expanding the activity of brown fat, beige fat or both in mice through genetic manipulation, drugs or transplantation suppresses metabolic disease ${ }^{15-17,47,60-63}$ (Table 1). These results imply that counterregulatory mechanisms (for example, increased food intake), which might have been predicted to offset the effects of expanded BAT activity to preserve energy balance, are not fully effective in mice. Notably, in some cases, the beiging of WAT and a highly correlated antiobesity effect happen without evidence of increased BAT function. For example, the hormone irisin raises energy expenditure through selective actions in beige adipocytes ${ }^{60}$. Similarly, transgenic expression of Prdm16 in all fat tissues promotes the beiging of WAT and resistance to obesity without increasing BAT mass or the amounts of $U c p 1$ mRNA ${ }^{16,17}$. In addition, transgenic expression of Ucp 1 in adipocytes suppresses obesity despite leading to a reduction in BAT mass ${ }^{17}$. These results raise an obvious question-do beige adipocytes have a more important physiological role than BAT in fighting obesity? This seems unlikely, given that a high-fat diet generally decreases the expression of thermogenic genes in WAT coincident with increases in WAT mass in mice ${ }^{59}$.

Mice with increased activity of brown fat, beige fat or both resist weight gain but also display improvements in systemic metabolism, including improved glucose tolerance and increased insulin sensitivity $15,16,60,64$. Along these lines, activated brown fat takes up and metabolizes large quantities of lipid from the bloodstream ${ }^{65}$, which has beneficial effects on metabolism. In models in which the activity of beige fat seems to be selectively increased, such as mice with transgenic expression of Prdm16 in their fat tissue ${ }^{16}$ and irisin-treated mice ${ }^{60}$, the improvement in glucose tolerance seems disproportional to the modest effects on body weight. We speculate that the increased proportion of beige to white adipocytes in WAT modulates systemic insulin action through nonthermogenic mechanisms, perhaps by altering the secretome of adipose tissue. Additionally, thermogenic fat cells, not yet classified as brown or beige, that surround blood vessels (perivascular adipose) have been suggested to protect against the development of atherosclerosis ${ }^{66}$. Thus, the potential therapeutic uses of brown and beige fat go beyond obesity and should be considered for various metabolic disturbances, including type 2 diabetes, insulin resistance, atherosclerosis and lipid disorders.

\section{Sympathetic nerve control of brown and beige fat}

Cold is a dominant regulator of many aspects of BAT biology. Mice lacking BAT activity are cold intolerant because of defective nonshivering thermogenesis ${ }^{53}$. Cold, sensed by various mechanisms, including thermoreceptors in the skin, elicits sympathetic outflow to BAT through an intricate neural circuitry (reviewed in ref. 67). In addition to nerve terminals, alternatively activated macrophages in BAT produce catecholamines in response to cold ${ }^{68}$. Norepinephrine agonizes adrenergic receptors on adipocytes, which triggers a signal transduction cascade that leads to adaptive increases in the expression of thermogenic genes ${ }^{69}$ (Fig. 3). Prolonged cold exposure also stimulates the proliferation and differentiation of brown precursor cells to expand BAT mass and increase thermogenic capacity ${ }^{70}$. Conversely, at warmer housing temperatures or in surgically denervated BAT, the expression of Ucp 1 and other thermogenic factors are substantially reduced in mice ${ }^{71,72}$.

Sympathetic nerve activity also acutely stimulates heat production by activating Ucp1 function. Classic studies have shown that fatty acids, rapidly released from lipid droplets in response to nerve activity, increase proton leak through UCP1 (reviewed in ref. 73). Recently, Fedorenko et al. ${ }^{74}$ discovered that long-chain fatty acids generated in the inner mitochondrial membrane by phospholipase A2 (Pla2) bind Ucp1 directly and are required for proton transport (Fig. 3). An important but often overlooked tenet is that UCP1 does not increase the respiratory activity of cells under basal conditions ${ }^{75,76}$. Therefore, therapeutic approaches that expand brown adipocytes, beige adipocytes or both without also promoting activation could be unproductive. However, in many people, an expanded brown fat compartment, beige fat compartment or both may be sufficiently activated by daily tonic stimuli (for example, food, cold and exercise) to achieve therapeutic effects.

Cold is also a classic activator of beige adipocyte development and function. Mice housed in the cold undergo a marked remodeling of their WAT that is characterized by an accumulation of beige adipocytes $^{7}$. This effect can be mimicked by treating mice with $\beta 3$-adrenergic activators such as CL 316,243 (refs. 7,30,61,62,77-80). Interestingly, the propensity of WAT depots to undergo beiging is highly correlated with their density of sympathetic nerve fibers ${ }^{81}$. However, other adipose cell- and/or tissue-autonomous factors must be involved, as systemic $\beta 3$-agonist administration (thereby bypassing the central nervous system) causes certain depots to beige more than others $^{33}$. Many of the effects of chronic cold on adipose tissues are recapitulated in mice that have elevated expression of forkhead box protein C2 (Foxc2) in adipocytes ${ }^{15}$. Specifically, Foxc2 increases BAT mass, induces beige fat cell development, drives mitochondrial biogenesis and promotes angiogenesis in fat tissue ${ }^{82-84}$. Foxc2 functions in fat cells to a large extent by driving the expression of the $\mathrm{R} 1 \alpha$ regulatory subunit of protein kinase A (PKA, encoded by Prkar1a) ${ }^{15,85}$, thus sensitizing adipocytes to the effects of catecholamines. These results suggest that the adipocytes instigate most of the tissue remodeling that occurs in response to norepinephrine.

The discovery of the mouse $\beta 3$-adrenergic receptor ( $\beta 3-\mathrm{AR})$, which is expressed mainly in fat and whose agonism activates thermogenesis (reviewed in ref. 72), generated tremendous excitement for therapeutic possibilities in humans. However, treatment of humans with 


\section{REVIEW}

Figure 3 Catecholamine and natriuretic induction of thermogenesis. Sympathetic neurons exocytose catecholamines (dark green circles), which bind to $\beta$-adrenoreceptors, leading to activation of adenylyl cyclase (AC), increased cyclic AMP (cAMP; light green circles) concentrations and enhanced PKA activity. Natriuretic peptides (NP; red circles) bind natriuretic peptide receptor $A$ (Npra), which activates guanylyl cyclase (GC) to increase the concentrations of cyclic GMP (cGMP; pink circles), leading to activation of PKG. Activated PKA and PKG use similar mechanisms to drive transcriptional responses in brown adipocytes through the activity of phosphorylated Creb and p38 Mapk. Specifically, p38 Mapk phosphorylates and activates Atf2 and Pgc- $1 \alpha$, which induce the transcription of downstream thermogenic genes, including Ucp 1. Pgc- $1 \alpha$ binds DNA through interactions with Ppar- $\gamma$, Ppar- $\alpha$, retinoid $X$ receptors (Rxrs) and thyroid receptor (TFX). Additionally, catecholamines increase the amounts of miR-196a, resulting in increased Clebp $\beta$ expression, which helps drive the thermogenic gene program. Importantly, activation of PKA and PKG also acutely induces lipolysis. The free fatty acids (FFA; blue circles) released from lipid droplets are oxidized by mitochondria to produce heat. Proton leak through Ucp1 is activated by long-chain fatty acids (LCFA; green circles) released from the mitochondrial membrane by Pla2. AR, adrenergic receptor; P, phosphate; Gs, a G protein subunit.

$\beta 3$-AR agonists never lived up to the forecasted predictions ${ }^{86}$. The observed difficulties seemed to be due to receptor differences between mice and humans, leading to off-target effects in humans, as well as poor pharmacokinetic properties and oral bioavailability ${ }^{87}$. These problems, compounded with the previously held tenet that adults have very little BAT, caused many companies to abandon their development of $\beta 3$-AR agonists for the treatment of obesity. Future studies should consider whether $\beta 3$-AR agonists could be used in combination with recruiters of brown fat, beige fat or both. Alternatively, it would be worth considering whether prescribed cold exposure could be used to activate brown fat, beige fat or both after augmentation by other pathways.

Cold exposure, which induces thermogenic features in adipose cells, also affects the developmental programs of other cell types in adipose tissue to coordinate and optimize heat production. For example, and as noted above, cold activates alternatively activated macrophages in BAT to produce catecholamines ${ }^{68}$. Cold also stimulates sympathetic nerve branching and recruitment during the browning response of $\mathrm{WAT}^{81}$. In addition, cold exposure induces the sprouting and growth of blood vessels in adipose to facilitate oxygen delivery

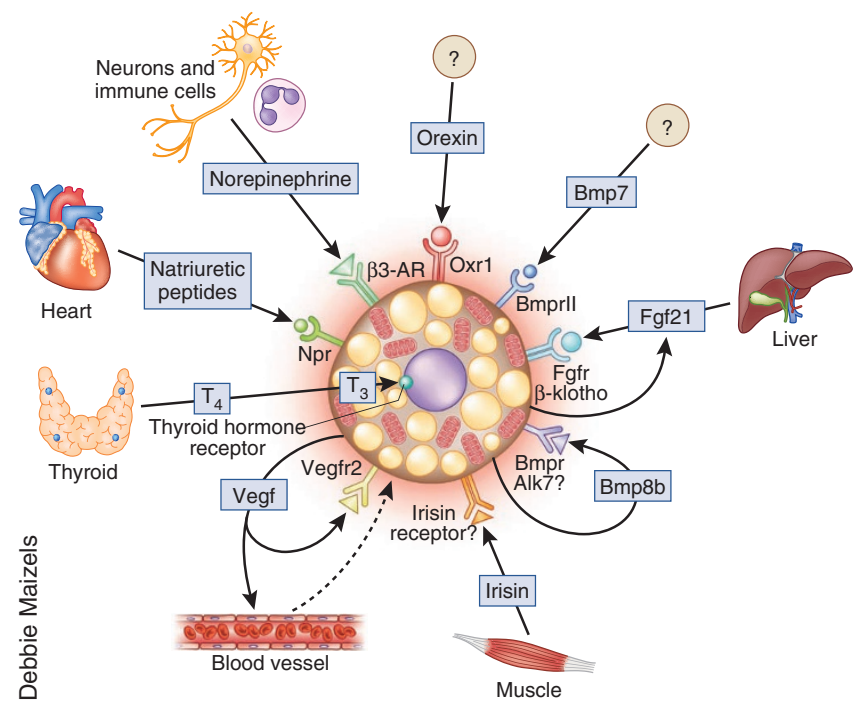

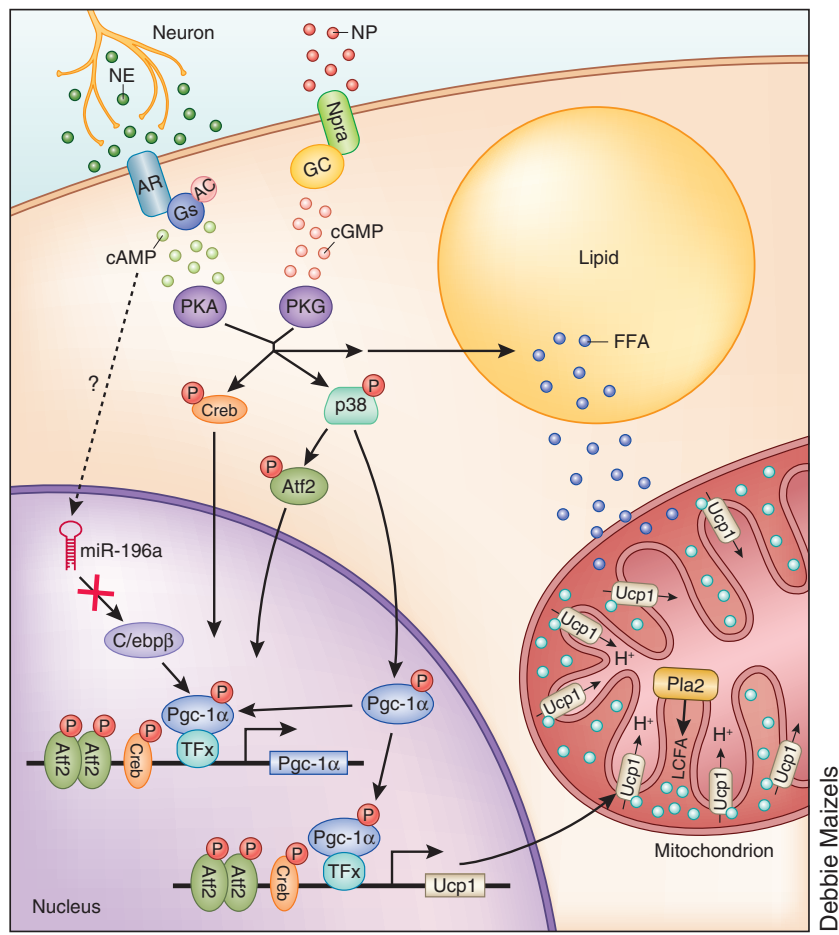

and heat exchange $\mathrm{e}^{70,72,88}$. This angiogenic effect is regulated through increased production of vascular endothelial growth factor (Vegf) by a mechanism that does not involve hypoxia ${ }^{89-91}$. Interestingly, Vegf secreted by adipose tissue also enhances the recruitment of brown and beige adipocytes through an unknown mechanism (Fig. 4). In cultured brown adipocytes, Vegf enhanced cell survival and proliferation, whereas VEGF-neutralizing antibodies caused apoptosis ${ }^{92}$. Notably, overexpression of Vegf in adipose tissues of mice increases BAT mass, stimulates beiging and promotes a healthy metabolic profile ${ }^{93,94}$. Vegf inhibition has also been shown to reduce metabolic disease in mice, although this effect was in the context of obese WAT that was already dysfunctional ${ }^{94,95}$. Further studies will be needed to elucidate the mechanism(s) by which VEGF manipulates the fate of adipose tissue under different metabolic states.

\section{PGC- $1 \alpha$ controls the thermogenic activation of adipocytes}

Pgc- $1 \alpha$ was discovered as a cold-induced interacting partner of Ppar- $\gamma$ in brown $\mathrm{fat}^{96}$. On the basis of hundreds of studies, PGC- $1 \alpha$ is now recognized as a master regulator of mitochondrial biogenesis and oxidative metabolism in many cell types. In adipocytes, Pgc- $1 \alpha$ also induces the expression of Ucp1 and other thermogenic components ${ }^{96,97}$. Surprisingly, however, BAT develops normally without Pgc- $1 \alpha^{98}$, probably because of compensation by the related family member

Figure 4 Secreted factors that recruit brown adipocytes, beige adipocytes or both. In rodents, a number of tissues and cell types have been found to secrete factors that regulate brown and beige adipose activity through systemic, autocrine and paracrine mechanisms. Neurons and alternatively activated macrophages secrete norepinephrine; cardiac tissue secretes natriuretic peptides; liver and BAT secrete Fgf21; muscle secretes irisin; and thyroid secretes the hormone $T_{4}$ (which is then converted to $T_{3}$ ). BAT also produces Bmp8b and Vegf, which increase thermogenic function in an autocrine manner. Additionally, orexin and Bmp7 promote brown fat development, but their cellular source is unknown. Oxr1, oxidation resistance 1; Alk7 (also called Acvr1c), activin A receptor type 1C. 
Pgc-1 1 . Although it is not required for tissue development, Pgc-1 $\alpha$ is essential for cold-induced or $\beta$-agonist-induced thermogenic activation of brown adipocytes ${ }^{99,100}$ and the expression of thermogenic genes in $\mathrm{WAT}^{101}$ (Fig. 2). Thus, Pgc-1 $\alpha$ is a central transcriptional effector of adrenergic activation in thermogenic adipocytes.

Pgc- $1 \alpha$ expression and activity are regulated directly by the $\beta$-adrenergic signaling pathway ${ }^{102}$, providing a link between the physiological activator of brown fat thermogenesis and the transcriptional machinery in brown adipocytes (Fig. 3). Specifically, Pgc- $1 \alpha$ is phosphorylated and thereby activated by p38 mitogenactivated protein kinase (MAPK) in response to sympathetic stimulation ${ }^{102,103}$. Activated Pgc- $1 \alpha$ regulates the expression of thermogenic genes through its interactions with Ppar- $\gamma$, Ppar- $\alpha$, thyroid receptor and other factors $96,104,105$, although a detailed mechanism to account for its selective effects at brown fat-specific genes is lacking. Pgc1a transcription also increases in response to $\beta$-adrenergic agonists through increases in the function of activating transcription factor-2 (Atf2) ${ }^{102}$.

Several transcription factors suppress thermogenesis by interfering with Pgc- $1 \alpha$ activity (Fig. 2). For example, the retinoblastoma family members pRb (also called Rb1) and p107 (also called Rbl1) repress Pgc- $1 \alpha$ transcription to block the expression of brown genes in white adipose ${ }^{106,107}$. Notably, pRb activity declines during the $\beta$-adrenergicinduced beige conversion of WAT ${ }^{107}$. The nuclear co-repressor Rip140 (also called Nrip1) binds Pgc-1 $\alpha$ and blocks its transcriptional activity at certain target genes ${ }^{108}$. The nuclear receptor Lxr- $\alpha$ (also called Nr1h3) also blocks Ucp1 expression by recruiting Rip140 and displacing Pgc- $1 \alpha$ at an Lxr-binding site ${ }^{109}$.

\section{Specific functions for the general adipogenic machinery}

PPAR $\gamma$ and members of the $\mathrm{c} / \mathrm{EBP}$ protein family orchestrate the general differentiation program in all adipose lineages ${ }^{110}$ but are also deployed to activate specific thermogenic genes in brown and beige adipocytes. For example, $\mathrm{C} / \mathrm{ebp} \beta$ is present at higher amounts in BAT relative to WAT, and its amounts increase further in response to cold ${ }^{42}$. In WAT, $\beta$-adrenergic agonists increase the amounts of $\mathrm{C} / \mathrm{ebp} \beta$ through miRNA-mediated degradation of Hoxc8, a repressor of C/ebp $\beta$ transcription ${ }^{111}$ (Fig. 3). Loss of $\mathrm{C} / \mathrm{ebp} \beta$ is associated with defective thermogenesis, whereas increasing the amounts of $\mathrm{C} / \mathrm{ebp} \beta$ in white fat cells triggers a brown fat transcriptional profile $e^{42,112-114}$.

The master adipogenic factor Ppar- $\gamma$ also controls the expression of brown fat-specific genes, including $U c p 1$, particularly in response to $\beta$-adrenergic activators ${ }^{102,103,115}$. Genome-wide analyses have demonstrated that Ppar- $\gamma$ binds and regulates distinct target genes in brown and white fat cells ${ }^{116,117}$. We recently discovered that Ebf2, a helix-loop-helix transcription factor, regulates Ppar- $\gamma$ activity to drive the expression of Prdm16 and a brown fat fate ${ }^{116}$ (Fig. 2). Ebf2 seems to function, at least in part, by facilitating the recruitment of Ppar- $\gamma$ (and probably other factors) to brown fat-specific genes. Ebf2-deficient mice develop fatty tissue with the molecular and morphological characteristics of white fat in the areas where brown fat normally forms.

Activation of Ppar- $\gamma$ by synthetic TZD agonists enhances thermogenic gene expression in both white and brown adipocytes ${ }^{12,118-122}$. TZDs induce UCP1 expression and increase mitochondrial biogenesis in adipocytes from mice and humans ${ }^{12,36,123}$. This enables TZDtreated adipocytes to undergo UCP1-mediated increases in respiration in response to $\beta$-adrenergic activators ${ }^{12,36,43}$. Mechanistically, TZDs seem to act in large part through Prdm16 to activate a thermogenic program. In particular, TZD treatment stabilizes Prdm16 protein to increase its amounts in fat cells ${ }^{43}$ and also enhances the interaction of Prdm16 with Ppar- $\gamma$ (Fig. 2). Sirtuin 1 (Sirt1) has a role in this TZD-driven process by deacetylating Ppar- $\gamma$ to facilitate the docking of Prdm16. In vivo, activation of Sirt1 promotes the browning of WAT and resistance to obesity ${ }^{47}$, suggesting that Sirt1 activators might have a use as weight-loss agents.

In the clinic, TZDs, although associated with unwanted side effects, are highly effective in the treatment of type 2 diabetes by enhancing insulin action. Given that beige adipocytes improve insulin sensitivity, it is reasonable to speculate that TZDs may act, at least in part, by inducing beige fat development. However, non-TZD PPAR- $\gamma$ modulators such as MRL24 promote insulin sensitivity but have little effect on Ucp1 expression ${ }^{43,124}$. Moreover, TZDs are associated with weight gain and increased adipocyte development in rodents and humans rather than weight loss. This effect may be due to a blunting effect that TZDs have on the sympathetic activation of adipocytes ${ }^{125,126}$, which would block UCP1 function. As mentioned earlier, it would be worth exploring treatments that combine TZDs with UCP1 activators, such as $\beta 3$-selective adrenergic agonists.

\section{New brown- and beige-fat recruiters and activators}

Sympathetic nerve activity was previously widely believed to be the primary or only physiological signal that activates BAT thermogenesis and induces beige adipocyte development. Although $\beta$-AR signaling is undoubtedly a central regulator of these processes, several other hormones and factors have now been shown to regulate energy expenditure in adipose tissue (Fig. 3) and have been discussed comprehensively in recent reviews ${ }^{13,127,128}$. Here we describe secreted and systemic factors that affect brown and beige fat and seem to be particularly promising for therapeutic development.

Irisin. In skeletal muscle, Pgc-1 $\alpha$ orchestrates the adaptive response to exercise, including increased mitochondrial biogenesis, switching from fast to slow muscle fibers and angiogenesis ${ }^{129}$. Unexpectedly however, increasing the amounts of Pgc- $1 \alpha$ in muscle protects sedentary mice from obesity ${ }^{130}$. In a search for effectors of the enhanced energy expenditure in these animals, Spiegelman and his colleagues discovered that the WAT of Pgc- $1 \alpha$ transgenic mice contained more beige adipocytes than that of wild-type mice ${ }^{60}$. They identified Fndc5 (encoding fibronectin type III domain containing 5) as a Pgc-1 $\alpha$ target gene and showed that its product was secreted from myocytes in the form of a previously undiscovered hormone, which they called irisin. Irisin stimulates the browning of WAT through specific actions on the beige preadipocyte population ${ }^{10}$ (Fig. 4).

Circulating concentrations of irisin increase in mice and humans by exercise training. Remarkably, a modest increase in the serum concentrations of irisin in mice stimulates beige fat development, leading to enhanced glucose tolerance and suppressed weight gain ${ }^{60}$. Irisin is thus a compelling hormone for clinical development, as it has marked beneficial effects when used at near-physiological concentrations in mice.

Of course, as with any new hormone, there are many outstanding questions. What is the irisin receptor (or receptors) in beige fat precursors, and how does it signal to the transcriptional machinery? Is the cleavage of Fndc5 into irisin a regulated process? And what effects does irisin have on other tissues?

Fibroblast growth factor 21. Fibroblast growth factor 21 (FGF21) is a circulating hormone that regulates systemic energy levels and has 


\section{REVIEW}

become a focus of clinical trials for obesity, diabetes and cardiovascular disease. In BAT, Fgf21 expression is increased by cold exposure and has an important role in thermogenesis ${ }^{131,132}$. Interestingly, there is a marked burst of Fgf21 production from the neonate liver in response to suckling - this effect is probably crucial for activating BAT thermogenesis at a time when animals are especially vulnerable to hypothermia ${ }^{133}$. Consistent with this hypothesis, administration of Fgf21 to fasted neonates augments the thermogenic gene program in BAT. In WAT, Fgf2 1 increases the amounts of Pgc-1 $\alpha$ to drive beige adipocyte recruitment in response to cold ${ }^{134,135}$.

Fgf21 has many desirable effects on metabolism in fed animals, including increased glucose uptake into peripheral tissues, improved insulin sensitivity and weight reduction ${ }^{134,136,137}$. Some of these actions may be mediated, at least in part, by stimulating fatty acid oxidation and energy dissipation pathways in adipocytes. Unfortunately, however, Fgf21 has also been shown to cause bone loss, which will need to be overcome if this hormone is to be used for clinical applications in obesity ${ }^{138}$.

Natriuretic peptides. Atrial natriuretic peptide and brain-type natriuretic peptide are released by the heart in response to heart failure or pressure overload. These factors reduce blood volume, blood pressure and cardiac output by dilating blood vessels and promoting salt and fluid excretion from the kidneys. Atrial natriuretic peptide is also known to promote lipolysis in adipocytes. Notably, high circulating concentrations of natriuretic peptides have also been associated with weight loss in humans ${ }^{139,140}$.

Bordicchia et al. ${ }^{64}$ recently discovered that increased concentrations of natriuretic peptides in mice promote beige adipocyte development in WAT and increase thermogenic gene expression in BAT. These changes are due to a direct effect of natriuretic peptides on adipose cells. Mechanistically, natriuretic peptides trigger lipolysis and browning through activation of cyclic GMP-dependent protein kinase (PKG). PKG works in parallel with the more familiar $\beta$-adrenergic-PKA pathway to trigger lipolysis and stimulate thermogenesis (Fig. 3).

The effects of natriuretic peptides on brown and beige adipogenesis suggest that the control of adaptive thermogenesis is more complex than is currently appreciated. Cardiomyocytes, a cell type that is thought to have little crosstalk with adipocytes, can markedly alter the gene expression and function of adipose through the secretion of potent cardiometabolic hormones ${ }^{64}$. Importantly, cold increases the concentrations of natriuretic peptides, suggesting that this browning system may have evolved, perhaps in epicardial fat, to safeguard cardiac function in animals during cold exposure. Systemic elevation of the concentrations of natriuretic peptides would probably have many undesirable off-target effects, but pharmacological targeting of this pathway in adipocytes could be considered.

BAT activators with central and peripheral actions. Bmp $8 \mathrm{~b}$ is produced by mature brown fat cells and functions to amplify the thermogenic response of brown adipocytes to adrenergic activators ${ }^{141}$ (Fig. 4). Interestingly, Bmp8b is also expressed in certain hypothalamic nuclei. Injection into the brain with Bmp8b increases the sympathetic outflow to BAT but not other tissues and leads to weight loss in mice ${ }^{141}$. Although more studies are needed to assess the effect of Bmp8b on other tissues, Bmp8b is a promising target for therapeutics at this stage.

Other factors have been shown to augment BAT activity through both central and peripheral actions. For example, thyroid hormone directly induces the expression of thermogenic genes in brown adipocytes through the actions of thyroid receptors and also functions centrally to activate BAT ${ }^{142-144}$. Along similar lines, the neurotransmitter orexin augments BAT function by regulating sympathetic outflow and through directly promoting brown fat precursor differentiation ${ }^{145,146}$ (Fig. 4). Targeting molecules, such as BMP8B, orexin and thyroid hormone, that both recruit and activate brown fat may be particularly effective in promoting energy expenditure and weight loss in humans.

\section{Outlook and challenges}

There is persuasive evidence from animal models that enhancement of the function of brown adipocytes, beige adipocytes or both in humans could be very effective for treating type 2 diabetes and obesity. Moreover, there are now an extensive variety of factors and pathways that could potentially be targeted for therapeutic effects. In particular, the discoveries of circulating factors, such as irisin, Fgf 21 and natriuretic peptides, that enhance brown and beige fat function in mice have garnered tremendous interest. However, there are several issues to consider with regard to therapies targeted at brown fat, beige fat or both.

First, many of the thermogenic inducers, such as irisin, Bmp8b, orexin, natriuretic peptides and Sirt1, were only identified recently as having effects on the biology of brown and beige fat. Although the early findings are very promising, many more studies will be needed to assess the potency of these factors on brown and beige fat under a variety of experimental conditions. As a related point, very few studies have explored the mechanisms of brown and beige adipocyte recruitment in human cells and tissues. Given the depot-specific mechanisms of beige fat recruitment in mice, this trait is probably highly variable among human fat depots. Defining the cell type(s) within human fat depots that can undergo efficient thermogenic activation and examining which pathways promote this process will be an important avenue of future research.

Second, even if thermogenic tissue can be pharmacologically expanded in humans, it must still be efficiently activated. Most available studies have used mice housed below their thermoneutrality, which consequently increased the sympathetic outflow to fat. Thus, brown fat- and beige fat-based therapies will probably need to expand the number of thermogenic fat cells(s), activate them or both. Molecules, such as Bmp8b, that increase the sensitivity of brown fat cells to adrenergic stimuli could be particularly valuable.

Third, energy balance is tightly controlled by homeostatic mechanisms. Despite enormous fluctuations in food intake and physical activity, the average person shows relative stability in their weight over long periods of time. By virtue of this fact, most individuals that lose weight tend to gain it back. Even if brown fat thermogenesis can be ramped up to increase calorie consumption, the body may compensate for the calorie deficit by increasing hunger or increasing the metabolic efficiency of other tissues such as muscle.

\section{ACKNOWLEDGMENTS}

Because of space limitations, we respectfully note that we were unable to comprehensively cite many worthy contributions to the field. We would like to thank members of the Seale lab for helpful comments and discussion. This work is supported by National Institute of General Medicine Sciences, US National Institutes of Health award DP2OD007288 and a Searle Scholars Award to P.S.

\section{COMPETING FINANCIAL INTERESTS}

The authors declare no competing financial interests.

Reprints and permissions information is available online at http://www.nature.com/ reprints/index.html. 
1. Lloyd-Jones, D. et al. Heart disease and stroke statistics-2009 update: a report from the American Heart Association Statistics Committee and Stroke Statistics Subcommittee. Circulation 119, e21-e181 (2009).

2. Bornfeldt, K.E. \& Tabas, I. Insulin resistance, hyperglycemia, and atherosclerosis. Cell Metab. 14, 575-585 (2011).

3. Cai, L., Lubitz, J., Flegal, K.M. \& Pamuk, E.R. The predicted effects of chronic obesity in middle age on medicare costs and mortality. Med. Care 48, 510-517 (2010)

4. Hammond, R.A. \& Levine, R. The economic impact of obesity in the United States. Diabetes Metab. Syndr. Obes. 3, 285-295 (2010).

5. Olshansky, S.J. et al. A potential decline in life expectancy in the United States in the $21^{\text {st }}$ century. N. Engl. J. Med. 352, 1138-1145 (2005).

6. Ricquier, D. Uncoupling protein 1 of brown adipocytes, the only uncoupler: a historical perspective. Front. Endocrinol. (Lausanne) 2, 85 (2012).

7. Vitali, A. et al. The adipose organ of obesity-prone C57BL/6J mice is composed of mixed white and brown adipocytes. J. Lipid Res. 53, 619-629 (2012).

8. Seale, P. et al. PRDM16 controls a brown fat/skeletal muscle switch. Nature 454, 961-967 (2008).

9. Xue, B. et al. Genetic variability affects the development of brown adipocytes in white fat but not in interscapular brown fat. J. Lipid Res. 48, 41-51 (2007).

10. Wu, J. et al. Beige adipocytes are a distinct type of thermogenic fat cell in mouse and human. Cell 150, 366-376 (2012)

11. Sharp, L.Z. et al. Human BAT possesses molecular signatures that resemble beige/brite cells. PLOS ONE 7, e49452 (2012).

12. Petrovic, N. et al. Chronic peroxisome proliferator-activated receptor $\gamma$ (PPAR $\gamma$ ) activation of epididymally derived white adipocyte cultures reveals a population of thermogenically competent, UCP1-containing adipocytes molecularly distinct from classic brown adipocytes. J. Biol. Chem. 285, 7153-7164 (2010).

13. Wu, J., Cohen, P. \& Spiegelman, B.M. Adaptive thermogenesis in adipocytes: is beige the new brown? Genes Dev. 27, 234-250 (2013).

14. Klaus, S., Ely, M., Encke, D. \& Heldmaier, G. Functional assessment of white and brown adipocyte development and energy metabolism in cell culture. Dissociation of terminal differentiation and thermogenesis in brown adipocytes. J. Cell Sci. 108, 3171-3180 (1995).

15. Cederberg, A. et al. FOXC2 is a winged helix gene that counteracts obesity, hypertriglyceridemia, and diet-induced insulin resistance. Cell 106, 563-573 (2001).

16. Seale, P. et al. Prdm16 determines the thermogenic program of subcutaneous white adipose tissue in mice. J. Clin. Invest. 121, 96-105 (2011).

17. Kopecky, J., Clarke, G., Enerback, S., Spiegelman, B. \& Kozak, L.P. Expression of the mitochondrial uncoupling protein gene from the aP2 gene promoter prevents genetic obesity. J. Clin. Invest. 96, 2914-2923 (1995).

18. Cypess, A.M. et al. Identification and importance of brown adipose tissue in adult humans. N. Engl. J. Med. 360, 1509-1517 (2009).

19. Nedergaard, J., Bengtsson, T. \& Cannon, B. Unexpected evidence for active brown adipose tissue in adult humans. Am. J. Physiol. Endocrinol. Metab. 293, E444-E452 (2007).

20. Saito, M. et al. High incidence of metabolically active brown adipose tissue in healthy adult humans: effects of cold exposure and adiposity. Diabetes $\mathbf{5 8}$, 1526-1531 (2009).

21. van Marken Lichtenbelt, W.D. et al. Cold-activated brown adipose tissue in healthy men. N. Engl. J. Med. 360, 1500-1508 (2009).

22. Virtanen, K.A. et al. Functional brown adipose tissue in healthy adults. N. Engl. J. Med. 360, 1518-1525 (2009)

23. Harper, J.A., Dickinson, K. \& Brand, M.D. Mitochondrial uncoupling as a target for drug development for the treatment of obesity. Obes. Rev. 2, 255-265 (2001)

24. Heaton, J.M. The distribution of brown adipose tissue in the human. J. Anat. 112, 35-39 (1972).

25. Lidell, M.E. et al. Evidence for two types of brown adipose tissue in humans. Nat. Med. b, 631-634 (2013).

26. Sanchez-Gurmaches, J. et al. PTEN loss in the Myf5 lineage redistributes body fat and reveals subsets of white adipocytes that arise from Myf5 precursors. Cell Metab. 16, 348-362 (2012).

27. Lepper, C. \& Fan, C.M. Inducible lineage tracing of Pax7-descendant cells reveals embryonic origin of adult satellite cells. Genesis 48, 424-436 (2010).

28. Timmons, J.A. et al. Myogenic gene expression signature establishes that brown and white adipocytes originate from distinct cell lineages. Proc. Natl. Acad. Sci. USA 104, 4401-4406 (2007).

29. Forner, F. et al. Proteome differences between brown and white fat mitochondria reveal specialized metabolic functions. Cell Metab. 10, 324-335 (2009).

30. Himms-Hagen, J et al. Multilocular fat cells in WAT of CL-316243-treated rats derive directly from white adipocytes. Am. J. Physiol. Cell Physiol. 279, C670-C681 (2000).

31. Wang, Q.A., Tao, C., Gupta, R.K. \& Scherer, P.E. Tracking adipogenesis during white adipose tissue development, expansion and regeneration. Nat. Med. advance online publication, doi:10.1038/nm.3324 (1 September 2013).

32. Rosenwald, M., Perdikari, A., Rulicke, T. \& Wolfrum, C. Bi-directional interconversion of brite and white adipocytes. Nat. Cell Biol. 15, 659-667 (2013).

33. Barbatelli, G. et al. The emergence of cold-induced brown adipocytes in mouse white fat depots is determined predominantly by white to brown adipocyte transdifferentiation. Am. J. Physiol. Endocrinol. Metab. 298, E1244-E1253 (2010).
34. Lee, Y.H., Petkova, A.P., Mottillo, E.P. \& Granneman, J.G. In vivo identification of bipotential adipocyte progenitors recruited by $\beta 3$-adrenoceptor activation and high-fat feeding. Cell Metab. 15, 480-491 (2012).

35. Berry, R. \& Rodeheffer, M.S. Characterization of the adipocyte cellular lineage in vivo. Nat. Cell Biol. 15, 302-308 (2013).

36. Elabd, C. et al. Human multipotent adipose-derived stem cells differentiate into functional brown adipocytes. Stem Cells 27, 2753-2760 (2009).

37. Jespersen, N.Z. et al. A classical brown adipose tissue mRNA signature partly overlaps with brite in the supraclavicular region of adult humans. Cell Metab. $\mathbf{1 7}$ 798-805 (2013).

38. Cypess, A.M. et al. Anatomical localization, gene expression profiling and functional characterization of adult human neck brown fat. Nat. Med. 19 635-639 (2013).

39. Seale, P. et al. Transcriptional control of brown fat determination by PRDM16. Cell Metab. 6, 38-54 (2007).

40. Lee, P. et al. High prevalence of brown adipose tissue in adult humans. J. Clin. Endocrinol. Metab. 96, 2450-2455 (2011).

41. Hondares, E. et al. Peroxisome proliferator-activated receptor $\alpha$ (PPAR $\alpha)$ induces PPAR $\gamma$ coactivator $1 \alpha$ (PGC-1 $\alpha$ ) gene expression and contributes to thermogenic activation of brown fat: involvement of PRDM16, J. Biol. Chem. 286, 43112-43122 (2011)

42. Kajimura, S. et al. Initiation of myoblast to brown fat switch by a PRDM16-C/ EBP- $\beta$ transcriptional complex. Nature 460, 1154-1158 (2009).

43. Ohno, H., Shinoda, K., Spiegelman, B.M. \& Kajimura, S. PPAR $\gamma$ agonists induce a white-to-brown fat conversion through stabilization of PRDM16 protein Cell Metab. 15, 395-404 (2012).

44. Tseng, Y.H. et al. New role of bone morphogenetic protein 7 in brown adipogenesis and energy expenditure. Nature 454, 1000-1004 (2008).

45. Schulz, T.J. et al. Identification of inducible brown adipocyte progenitors residing in skeletal muscle and white fat. Proc. Natl. Acad. Sci. USA 108, 143-148 (2011).

46. Schulz, T.J. et al. Brown-fat paucity due to impaired BMP signalling induces compensatory browning of white fat. Nature 495, 379-383 (2013).

47. Qiang, L. et al. Brown remodeling of white adipose tissue by SirT1-dependent deacetylation of Ppary. Cell 150, 620-632 (2012).

48. Trajkovski, M., Ahmed, K., Esau, C.C. \& Stoffel, M. MyomiR-133 regulates brown fat differentiation through Prdm16. Nat. Cell Biol. 14, 1330-1335 (2012).

49. Liu, W. et al. miR-133a regulates adipocyte browning in vivo. PLoS Genet. 9 , e1003626 (2013).

50. Yin, $\mathrm{H}$. et al. MicroRNA-133 controls brown adipose determination in skeleta muscle satellite cells by targeting Prdm16. Cell Metab. 17, 210-224 (2013).

51. Rothwell, N.J. \& Stock, M.J. A role for brown adipose tissue in diet-induced thermogenesis. Nature 281, 31-35 (1979).

52. Lowell, B.B. et al. Development of obesity in transgenic mice after genetic ablation of brown adipose tissue. Nature 366, 740-742 (1993).

53. Enerbäck, S. et al. Mice lacking mitochondrial uncoupling protein are coldsensitive but not obese. Nature 387, 90-94 (1997).

54. Feldmann, H.M., Golozoubova, V., Cannon, B. \& Nedergaard, J. UCP1 ablation induces obesity and abolishes diet-induced thermogenesis in mice exempt from thermal stress by living at thermoneutrality. Cell Metab. 9, 203-209 (2009).

55. Anunciado-Koza, R.P. et al. Inactivation of the mitochondrial carrier SLC25A25 (ATP-Mg2+/Pi transporter) reduces physical endurance and metabolic efficiency in mice. J. Biol. Chem. 286, 11659-11671 (2011).

56. Bal, N.C. et al. Sarcolipin is a newly identified regulator of muscle-based thermogenesis in mammals. Nat. Med. 18, 1575-1579 (2012).

57. Kontani, Y. et al. UCP1 deficiency increases susceptibility to diet-induced obesity with age. Aging Cell 4, 147-155 (2005)

58. Ma, S.W., Foster, D.O., Nadeau, B.E. \& Triandafillou, J. Absence of increased oxygen consumption in brown adipose tissue of rats exhibiting "cafeteria" dietinduced thermogenesis. Can. J. Physiol. Pharmacol. 66, 1347-1354 (1988).

59. Fromme, T. \& Klingenspor, M. Uncoupling protein 1 expression and high-fat diets. Am. J. Physiol. Regul. Integr. Comp. Physiol. 300, R1-R8 (2011).

60. Boström, P. et al. A PGC1- $\alpha$-dependent myokine that drives brown-fat-like development of white fat and thermogenesis. Nature 481, 463-468 (2012).

61. Collins, S., Daniel, K.W., Petro, A.E. \& Surwit, R.S. Strain-specific response to 33 -adrenergic receptor agonist treatment of diet-induced obesity in mice. Endocrinology 138, 405-413 (1997).

62. Guerra, C., Koza, R.A., Yamashita, H., Walsh, K. \& Kozak, L.P. Emergence of brown adipocytes in white fat in mice is under genetic control. Effects on body weight and adiposity. J. Clin. Invest. 102, 412-420 (1998).

63. Stanford, K.I. et al. Brown adipose tissue regulates glucose homeostasis and insulin sensitivity. J. Clin. Invest. 123, 215-223 (2013).

64. Bordicchia, M. et al. Cardiac natriuretic peptides act via p38 MAPK to induce the brown fat thermogenic program in mouse and human adipocytes. J. Clin. Invest. 122, 1022-1036 (2012).

65. Bartelt, A. et al. Brown adipose tissue activity controls triglyceride clearance. Nat. Med. 17, 200-205 (2011)

66. Chang, L. et al. Loss of perivascular adipose tissue on peroxisome proliferatoractivated receptor- $\gamma$ deletion in smooth muscle cells impairs intravascular thermoregulation and enhances atherosclerosis. Circulation 126, 1067-1078 (2012).

67. Morrison, S.F., Madden, C.J. \& Tupone, D. Central control of brown adipose tissue thermogenesis. Front. Endocrinol. (Lausanne) 3, 5 (2012). 
68. Nguyen, K.D. et al. Alternatively activated macrophages produce catecholamines to sustain adaptive thermogenesis. Nature 480, 104-108 (2011).

69. Collins, S. $\beta$-adrenoceptor signaling networks in adipocytes for recruiting stored fat and energy expenditure. Front. Endocrinol. (Lausanne) 2, 102 (2012).

70. Bukowiecki, L., Collet, A.J., Follea, N., Guay, G. \& Jahjah, L. Brown adipose tissue hyperplasia: a fundamental mechanism of adaptation to cold and hyperphagia. Am. J. Physiol. 242, E353-E359 (1982).

71. Desautels, M., Dulos, R.A. \& Mozaffari, B. Selective loss of uncoupling protein from mitochondria of surgically denervated brown adipose tissue of cold-acclimated mice. Biochem. Cell Biol. 64, 1125-1134 (1986).

72. Cannon, B. \& Nedergaard, J. Brown adipose tissue: function and physiological significance. Physiol. Rev. 84, 277-359 (2004).

73. Nicholls, D.G. The physiological regulation of uncoupling proteins. Biochim. Biophys. Acta 1757, 459-466 (2006).

74. Fedorenko, A., Lishko, P.V. \& Kirichok, Y. Mechanism of fatty-acid-dependent UCP1 uncoupling in brown fat mitochondria. Cell 151, 400-413 (2012).

75. Jastroch, M., Hirschberg, V. \& Klingenspor, M. Functional characterization of UCP1 in mammalian HEK293 cells excludes mitochondrial uncoupling artefacts and reveals no contribution to basal proton leak. Biochim. Biophys. Acta 1817, 1660-1670 (2012).

76. Shabalina, I.G. et al. Uncoupling protein-1 is not leaky. Biochim. Biophys. Acta 1797, 773-784 (2010).

77. Barbatelli, G. et al. The emergence of cold-induced brown adipocytes in mouse white fat depots is predominantly determined by white to brown adipocyte transdifferentiation. Am. J. Physiol. Endocrinol. Metab. 298, E1244-E1253 (2010).

78. Cousin, B. et al. Occurrence of brown adipocytes in rat white adipose tissue: molecular and morphological characterization. J. Cell Sci. 103, 931-942 (1992).

79. Huttunen, P., Hirvonen, J. \& Kinnula, V. The occurrence of brown adipose tissue in outdoor workers. Eur. J. Appl. Physiol. Occup. Physiol. 46, 339-345 (1981).

80. Young, P., Arch, J.R. \& Ashwell, M. Brown adipose tissue in the parametrial fat pad of the mouse. FEBS Lett. 167, 10-14 (1984).

81. Murano, I., Barbatelli, G., Giordano, A. \& Cinti, S. Noradrenergic parenchymal nerve fiber branching after cold acclimatisation correlates with brown adipocyte density in mouse adipose organ. J. Anat. 214, 171-178 (2009).

82. Kim, J.K. et al. Adipocyte-specific overexpression of FOXC2 prevents diet-induced increases in intramuscular fatty acyl $\mathrm{CoA}$ and insulin resistance. Diabetes 54, 1657-1663 (2005).

83. Xue, Y. et al. FOXC2 controls Ang-2 expression and modulates angiogenesis, vascular patterning, remodeling, and functions in adipose tissue. Proc. Natl. Acad. Sci. USA 105, 10167-10172 (2008).

84. Lidell, M.E. et al. The adipocyte-expressed forkhead transcription factor Foxc2 regulates metabolism through altered mitochondrial function. Diabetes 60, 427-435 (2011).

85. Dahle, M.K. et al. Mechanisms of FOXC2- and FOXD1-mediated regulation of the RI $\alpha$ subunit of CAMP-dependent protein kinase include release of transcriptional repression and activation by protein kinase $\mathrm{B} \alpha$ and cAMP. J. Biol. Chem. 277, 22902-22908 (2002).

86. Buemann, B., Toubro, S. \& Astrup, A. Effects of the two $\beta 3$-agonists, ZD7114 and ZD2079 on 24 hour energy expenditure and respiratory quotient in obese subjects. Int. J. Obes. Relat. Metab. Disord. 24, 1553-1560 (2000).

87. Arch, J.R. $\beta 3$-adrenoceptor agonists: potential, pitfalls and progress. Eur. J. Pharmacol. 440, 99-107 (2002).

88. Foster, D.O. \& Frydman, M.L. Nonshivering thermogenesis in the rat. II. Measurements of blood flow with microspheres point to brown adipose tissue as the dominant site of the calorigenesis induced by noradrenaline. Can. J. Physiol. Pharmacol. 56, 110-122 (1978).

89. Xue, Y. et al. Hypoxia-independent angiogenesis in adipose tissues during cold acclimation. Cell Metab. 9, 99-109 (2009).

90. Asano, A., Morimatsu, M., Nikami, H., Yoshida, T. \& Saito, M. Adrenergic activation of vascular endothelial growth factor mRNA expression in rat brown adipose tissue: implication in cold-induced angiogenesis. Biochem. J. 328, 179-183 (1997).

91. Tonello, C. et al. Role of sympathetic activity in controlling the expression of vascular endothelial growth factor in brown fat cells of lean and genetically obese rats. FEBS Lett. 442, 167-172 (1999).

92. Bagchi, M. et al. Vascular endothelial growth factor is important for brown adipose tissue development and maintenance. FASEB J. 27, 3257-3271 (2013).

93. Elias, I. et al. Adipose tissue overexpression of vascular endothelial growth factor protects against diet-induced obesity and insulin resistance. Diabetes 61, 1801-1813 (2012).

94. Sun, K. et al. Dichotomous effects of VEGF-A on adipose tissue dysfunction. Proc. Natl. Acad. Sci. USA 109, 5874-5879 (2012).

95. Lu, X. et al. Resistance to obesity by repression of VEGF gene expression through induction of brown-like adipocyte differentiation. Endocrinology 153, 3123-3132 (2012).

96. Puigserver, P. et al. A cold-inducible coactivator of nuclear receptors linked to adaptive thermogenesis. Cell 92, 829-839 (1998).

97. Tiraby, C. et al. Acquirement of brown fat cell features by human white adipocytes. J. Biol. Chem. 278, 33370-33376 (2003).
98. Lin, J. et al. Defects in adaptive energy metabolism with CNS-linked hyperactivity in PGC-1 $\alpha$ null mice. Cell 119, 121-135 (2004).

99. Leone, T.C. et al. PGC- $1 \alpha$ deficiency causes multi-system energy metabolic derangements: muscle dysfunction, abnormal weight control and hepatic steatosis. PLoS Biol. 3, e101 (2005).

100. Uldry, M. et al. Complementary action of the PGC-1 coactivators in mitochondrial biogenesis and brown fat differentiation. Cell Metab. 3, 333-341 (2006).

101. Kleiner, S. et al. Development of insulin resistance in mice lacking PGC-1 $\alpha$ in adipose tissues. Proc. Natl. Acad. Sci. USA 109, 9635-9640 (2012).

102. Cao, W. et al. p38 mitogen-activated protein kinase is the central regulator of cyclic AMP-dependent transcription of the brown fat uncoupling protein 1 gene. Mol. Cell Biol. 24, 3057-3067 (2004)

103. Cao, W., Medvedev, A.V., Daniel, K.W. \& Collins, S. $\beta$-adrenergic activation of p38 MAP kinase in adipocytes: CAMP induction of the uncoupling protein 1 (UCP1) gene requires p38 MAP kinase. J. Biol. Chem. 276, 27077-27082 (2001).

104. Wulf, A. et al. T3-mediated expression of PGC-1 $\alpha$ via a far upstream located thyroid hormone response element. Mol. Cell Endocrinol. 287, 90-95 (2008).

105. Hondares, E. et al. Thiazolidinediones and rexinoids induce peroxisome proliferator-activated receptor-coactivator (PGC)- $1 \alpha$ gene transcription: an autoregulatory loop controls PGC- $1 \alpha$ expression in adipocytes via peroxisome proliferator-activated receptor- $\gamma$ coactivation. Endocrinology 147, 2829-2838 (2006).

106. Scimè, A. et al. $\mathrm{Rb}$ and $\mathrm{p} 107$ regulate preadipocyte differentiation into white versus brown fat through repression of PGC-1 $\alpha$. Cell Metab. 2, 283-295 (2005).

107. Hansen, J.B. et al. Retinoblastoma protein functions as a molecular switch determining white versus brown adipocyte differentiation. Proc. Natl. Acad. Sci. USA 101, 4112-4117 (2004).

108. Hallberg, M. et al. A functional interaction between RIP140 and PGC- $1 \alpha$ regulates the expression of the lipid droplet protein CIDEA. Mol. Cell Biol. 28, 6785-6795 (2008).

109. Wang, $H$. et al. Liver $X$ receptor $\alpha$ is a transcriptional repressor of the uncoupling protein 1 gene and the brown fat phenotype. Mol. Cell Biol. 28, 2187-2200 (2008).

110. Rosen, E.D. \& MacDougald, O.A. Adipocyte differentiation from the inside out. Nat. Rev. Mol. Cell Biol. 7, 885-896 (2006).

111. Mori, M., Nakagami, H., Rodriguez-Araujo, G., Nimura, K. \& Kaneda, Y. Essential role for miR-196a in brown adipogenesis of white fat progenitor cells. PLoS Biol. 10, e1001314 (2012).

112. Carmona, M.C. et al. Defective thermoregulation, impaired lipid metabolism, but preserved adrenergic induction of gene expression in brown fat of mice lacking C/EBPR. Biochem. J. 389, 47-56 (2005).

113. Karamanlidis, G., Karamitri, A., Docherty, K., Hazlerigg, D.G. \& Lomax, M.A. C/EBP $\beta$ reprograms white $3 \mathrm{~T} 3-\mathrm{L} 1$ preadipocytes to a brown adipocyte pattern of gene expression. J. Biol. Chem. 282, 24660-24669 (2007).

114. Tanaka, T., Yoshida, N., Kishimoto, T. \& Akira, S. Defective adipocyte differentiation in mice lacking the C/EBP $\beta$ and/or C/EBP $\delta$ gene. EMBO J. 16, 7432-7443 (1997).

115. Tai, T.A. et al. Activation of the nuclear receptor peroxisome proliferatoractivated receptor $\gamma$ promotes brown adipocyte differentiation. J. Biol. Chem. 271, 29909-29914 (1996).

116. Rajakumari, S. et al. EBF2 determines and maintains brown adipocyte identity. Cell Metab. 17, 562-574 (2013).

117. Siersbæk, M.S. et al. Genome-wide profiling of PPAR $\gamma$ in primary epididymal, inguinal, and brown adipocytes reveals depot-selective binding correlated with gene expression. Mol. Cell Biol. 32, 3452-3463 (2012).

118. Fukui, Y., Masui, S., Osada, S., Umesono, K. \& Motojima, K. A new thiazolidinedione, NC-2100, which is a weak PPAR- $\gamma$ activator, exhibits potent antidiabetic effects and induces uncoupling protein 1 in white adipose tissue of KKAy obese mice. Diabetes 49, 759-767 (2000).

119. Rong, J.X. et al. Adipose mitochondrial biogenesis is suppressed in $\mathrm{db} / \mathrm{db}$ and high-fat diet-fed mice and improved by rosiglitazone. Diabetes 56, 1751-1760 (2007).

120. Sell, H. et al. Peroxisome proliferator-activated receptor $\gamma$ agonism increases the capacity for sympathetically mediated thermogenesis in lean and ob/ob mice. Endocrinology 145, 3925-3934 (2004).

121. Vernochet, $\mathrm{C}$. et al. $\mathrm{C} / \mathrm{EBP} \alpha$ and the corepressors $\mathrm{CtBP} 1$ and $\mathrm{CtBP} 2$ regulate repression of select visceral white adipose genes during induction of the brown phenotype in white adipocytes by peroxisome proliferator-activated receptor $\gamma$ agonists. Mol. Cell Biol. 29, 4714-4728 (2009).

122. Wilson-Fritch, L. et al. Mitochondrial remodeling in adipose tissue associated with obesity and treatment with rosiglitazone. J. Clin. Invest. 114, 1281-1289 (2004).

123. Digby, J.E. et al. Thiazolidinedione exposure increases the expression of uncoupling protein 1 in cultured human preadipocytes. Diabetes 47, 138-141 (1998).

124. Choi, J.H. et al. Anti-diabetic drugs inhibit obesity-linked phosphorylation of PPAR $\gamma$ by Cdk5. Nature 466, 451-456 (2010).

125. Bakopanos, E. \& Silva, J.E. Thiazolidinediones inhibit the expression of $\beta 3$-adrenergic receptors at a transcriptional level. Diabetes 49, 2108-2115 (2000). 
126. Festuccia, W.T. et al. Peroxisome proliferator-activated receptor- $\gamma$-mediated positive energy balance in the rat is associated with reduced sympathetic drive to adipose tissues and thyroid status. Endocrinology 149, 2121-2130 (2008).

127. Bonet, M.L., Oliver, P. \& Palou, A. Pharmacological and nutritional agents promoting browning of white adipose tissue. Biochim. Biophys. Acta 1831, 969-985 (2013)

128. Villarroya, F. \& Vidal-Puig, A. Beyond the sympathetic tone: the new brown fat activators. Cell Metab. 17, 638-643 (2013).

129. Lira, V.A., Benton, C.R., Yan, Z. \& Bonen, A. PGC-1 $\alpha$ regulation by exercise training and its influences on muscle function and insulin sensitivity. Am. J. Physiol. Endocrinol. Metab. 299, E145-E161 (2010).

130. Wenz, T., Rossi, S.G., Rotundo, R.L., Spiegelman, B.M. \& Moraes, C.T. Increased muscle PGC- $1 \alpha$ expression protects from sarcopenia and metabolic disease during aging. Proc. Natl. Acad. Sci. USA 106, 20405-20410 (2009).

131. Chartoumpekis, D.V. et al. Brown adipose tissue responds to cold and adrenergic stimulation by induction of FGF21. Mol. Med. 17, 736-740 (2011).

132. Hondares, E. et al. Thermogenic activation induces FGF21 expression and release in brown adipose tissue. J. Biol. Chem. 286, 12983-12990 (2011).

133. Hondares, E. et al. Hepatic FGF21 expression is induced at birth via PPAR $\alpha$ in response to milk intake and contributes to thermogenic activation of neonatal brown fat. Cell Metab. 11, 206-212 (2010).

134. Coskun, T. et al. Fibroblast growth factor 21 corrects obesity in mice. Endocrinology $149,6018-6027$ (2008)

135. Fisher, F.M. et al. FGF21 regulates PGC-1 $\alpha$ and browning of white adipose tissues in adaptive thermogenesis. Genes Dev. 26, 271-281 (2012).

136. Kharitonenkov, A. et al. FGF-21 as a novel metabolic regulator. J. Clin. Invest. 115, 1627-1635 (2005)

137. Xu, J. et al. Fibroblast growth factor 21 reverses hepatic steatosis, increases energy expenditure, and improves insulin sensitivity in diet-induced obese mice. Diabetes 58, 250-259 (2009).

138. Wei, W. et al. Fibroblast growth factor 21 promotes bone loss by potentiating the effects of peroxisome proliferator-activated receptor $\gamma$. Proc. Natl. Acad. Sci. USA 109, 3143-3148 (2012).

139. Chainani-Wu, N. et al. Relation of B-type natriuretic peptide levels to body mass index after comprehensive lifestyle changes. Am. J. Cardiol. 105, 1570-1576 (2010)

140. Sengenès, C., Berlan, M., De Glisezinski, I., Lafontan, M. \& Galitzky, J. Natriuretic peptides: a new lipolytic pathway in human adipocytes. FASEB J. 14, 1345-1351 (2000)

141. Whittle, A.J. et al. BMP8B increases brown adipose tissue thermogenesis through both central and peripheral actions. Cell 149, 871-885 (2012).

142. de Jesus, L.A. et al. The type 2 iodothyronine deiodinase is essential for adaptive thermogenesis in brown adipose tissue. J. Clin. Invest. 108, 1379-1385 (2001).

143. López, M. et al. Hypothalamic AMPK and fatty acid metabolism mediate thyroid regulation of energy balance. Nat. Med. 16, 1001-1008 (2010).

144. Silva, J.E. Thermogenic mechanisms and their hormonal regulation. Physiol. Rev. 86, 435-464 (2006)

145. Sellayah, D., Bharaj, P. \& Sikder, D. Orexin is required for brown adipose tissue development, differentiation and function. Cell Metab. 14, 478-490 (2011).

146. Zhang, W. et al. Orexin neurons are indispensable for stress-induced thermogenesis in mice. J. Physiol. (Lond.) 588, 4117-4129 (2010).

147. Vegiopoulos, A. et al. Cyclooxygenase-2 controls energy homeostasis in mice by de novo recruitment of brown adipocytes. Science 328, 1158-1161 (2010).

148. Ortega-Molina, A. et al. Pten positively regulates brown adipose function, energy expenditure, and longevity. Cell Metab. 15, 382-394 (2012).

149. Stefl, B. et al. Brown fat is essential for cold-induced thermogenesis but not for obesity resistance in aP2-Ucp mice. Am. J. Physiol. 274, E527-E533 (1998).

150. Fournier, B. et al. Blockade of the activin receptor Ilb activates functional brown adipogenesis and thermogenesis by inducing mitochondrial oxidative metabolism. Mol. Cell Biol. 32, 2871-2879 (2012).

151. Koncarevic, A. et al. A novel therapeutic approach to treating obesity through modulation of TGF $\beta$ signaling. Endocrinology 153, 3133-3146 (2012).

152. Vila-Bedmar, R. et al. GRK2 contribution to the regulation of energy expenditure and brown fat function. FASEB J. 26, 3503-3514 (2012).

153. Zhang, Y. et al. Targeted deletion of thioesterase superfamily member 1 promotes energy expenditure and protects against obesity and insulin resistance. Proc. Natl. Acad. Sci. USA 109, 5417-5422 (2012).

154. Kiefer, F.W. et al. Retinaldehyde dehydrogenase 1 regulates a thermogenic program in white adipose tissue. Nat. Med. 18, 918-925 (2012).

155. Patwari, P. et al. The arrestin domain-containing 3 protein regulates body mass and energy expenditure. Cell Metab. 14, 671-683 (2011).

156. Singh, R. et al. Autophagy regulates adipose mass and differentiation in mice. J. Clin. Invest. 119, 3329-3339 (2009).

157. Wang, C. et al. ATF4 regulates lipid metabolism and thermogenesis. Cell Res. 20, 174-184 (2010)

158. Meakin, P.J. et al. Reduction in BACE1 decreases body weight, protects against diet-induced obesity and enhances insulin sensitivity in mice. Biochem. J. 441, 285-296 (2012)

159. Zhou, Z. et al. Cidea-deficient mice have lean phenotype and are resistant to obesity. Nat. Genet. 35, 49-56 (2003).
160. Toh, S.Y. et al. Up-regulation of mitochondrial activity and acquirement of brown adipose tissue-like property in the white adipose tissue of fsp27 deficient mice. PLOS ONE 3, e2890 (2008).

161. Perwitz, N. et al. Cannabinoid type 1 receptor blockade induces transdifferentiation towards a brown fat phenotype in white adipocytes. Diabetes Obes. Metab. 12 158-166 (2010).

162. Bale, T.L. et al. Corticotropin-releasing factor receptor-2-deficient mice display abnormal homeostatic responses to challenges of increased dietary fat and cold. Endocrinology 144, 2580-2587 (2003).

163. Armengol, J. et al. Pref-1 in brown adipose tissue: specific involvement in brown adipocyte differentiation and regulatory role of C/EBP $\delta$. Biochem. J. 443 , 799-810 (2012).

164. Tsukiyama-Kohara, K. et al. Adipose tissue reduction in mice lacking the translational inhibitor 4E-BP1. Nat. Med. 7, 1128-1132 (2001).

165. Yu, X.X. et al. Reduced adiposity and improved insulin sensitivity in obese mice with antisense suppression of 4E-BP2 expression. Am. J. Physiol. Endocrinol. Metab. 294, E530-E539 (2008).

166. Bjursell, M. et al. Improved glucose control and reduced body fat mass in free fatty acid receptor 2-deficient mice fed a high-fat diet. Am. J. Physiol. Endocrinol. Metab. 300, E211-E220 (2011)

167. Nakae, J. et al. Forkhead transcription factor FoxO1 in adipose tissue regulates energy storage and expenditure. Diabetes $\mathbf{5 7}, 563-576$ (2008).

168. Lin, L. et al. Ablation of ghrelin receptor reduces adiposity and improves insulin sensitivity during aging by regulating fat metabolism in white and brown adipose tissues. Aging Cell 10, 996-1010 (2011).

169. Satyanarayana, A., Klarmann, K.D., Gavrilova, O. \& Keller, J.R. Ablation of the transcriptional regulator Id1 enhances energy expenditure, increases insulin sensitivity, and protects against age and diet induced insulin resistance, and hepatosteatosis. FASEB J. 26, 309-323 (2012).

170. Chiang, S.H. et al. The protein kinase IKKe regulates energy balance in obese mice. Cell 138, 961-975 (2009).

171. Strom, K. et al. Attainment of brown adipocyte features in white adipocytes of hormone-sensitive lipase null mice. PLoS One 3, e1793 (2008).

172. Liu, W. et al. Low density lipoprotein (LDL) receptor-related protein 6 (LRP6) regulates body fat and glucose homeostasis by modulating nutrient sensing pathways and mitochondrial energy expenditure. J. Biol. Chem. 287, 7213-7223 (2012).

173. Zhang, C. et al. Inhibition of myostatin protects against diet-induced obesity by enhancing fatty acid oxidation and promoting a brown adipose phenotype in mice. Diabetologia 55, 183-193 (2012)

174. Picard, F. et al. SRC-1 and TIF2 control energy balance between white and brown adipose tissues. Cell 111, 931-941 (2002).

175. Christian, M. et al. RIP140-targeted repression of gene expression in adipocytes. Mol. Cell Biol. 25, 9383-9391 (2005).

176. Leonardsson, G. et al. Nuclear receptor corepressor RIP140 regulates fat accumulation. Proc. Natl. Acad Sci. USA 101, 8437-8442 (2004).

177. Powelka, A.M. et al. Suppression of oxidative metabolism and mitochondria biogenesis by the transcriptional corepressor RIP140 in mouse adipocytes. J. Clin. Invest. 116, 125-136 (2006).

178. Czyzyk, T.A. et al. Mice lacking delta-opioid receptors resist the development of diet-induced obesity. FASEB J. 26, 3482-3492 (2012).

179. Kang, H.W. et al. Mice lacking Pctp/StarD2 exhibit increased adaptive thermogenesis and enlarged mitochondria in brown adipose tissue. J. Lipid Res. 50, 2212-2221 (2009)

180. Cummings, D.E. et al. Genetically lean mice result from targeted disruption of the RIIB subunit of protein kinase A. Nature 382, 622-626 (1996).

181. Huang, W., Bansode, R.R., Bal, N.C., Mehta, M. \& Mehta, K.D. Protein kinase $C \beta$ deficiency attenuates obesity syndrome of ob/ob mice by promoting white adipose tissue remodeling. J. Lipid Res. 53, 368-378 (2012).

182. Auffret, J. et al. Beige differentiation of adipose depots in mice lacking prolactin receptor protects against high-fat-diet-induced obesity. FASEB J. 26, 3728-3737 (2012).

183. Sampath, H. et al. Skin-specific deletion of stearoyl-CoA desaturase-1 alters skin lipid composition and protects mice from high fat diet-induced obesity. J. Biol Chem. 284, 19961-19973 (2009).

184. Mori, H. et al. Secreted frizzled-related protein 5 suppresses adipocyte mitochondrial metabolism through WNT inhibition. J. Clin. Invest. 122, 2405-2416 (2012).

185. Yadav, H. et al. Protection from obesity and diabetes by blockade of TGF-B/Smad3 signaling. Cell Metab. 14, 67-79 (2011).

186. Romanatto, T. et al. Deletion of tumor necrosis factor- $\alpha$ receptor 1 (TNFR1) protects against diet-induced obesity by means of increased thermogenesis. J. Biol. Chem. 284, 36213-36222 (2009)

187. Ye, L. et al. TRPV4 is a regulator of adipose oxidative metabolism, inflammation, and energy homeostasis. Cell 151, 96-110 (2012).

188. Pan, D., Fujimoto, M., Lopes, A. \& Wang, Y.X. Twist-1 is a PPAR - -inducible, negative-feedback regulator of PGC-1 $\alpha$ in brown fat metabolism. Cell 137, 73-86 (2009).

189. Watson, E. et al. Analysis of knockout mice suggests a role for VGF in the control of fat storage and energy expenditure. BMC Physiol. 9, 19 (2009). 